\title{
Slow Spatial Recruitment of Neocortex during Secondarily Generalized Seizures and Its Relation to Surgical Outcome
}

\author{
니ouis-Emmanuel Martinet, ${ }^{1}$ Omar J. Ahmed, ${ }^{2}$ Kyle Q. Lepage, ${ }^{1}$ Sydney S. Cash, ${ }^{2}$ and Mark A. Kramer ${ }^{1}$ \\ ${ }^{1}$ Department of Mathematics and Statistics, Boston University, Boston, Massachusetts 02215 and ${ }^{2}$ Department of Neurology, Massachusetts General \\ Hospital, Boston, Massachusetts 02114
}

Understanding the spatiotemporal dynamics of brain activity is crucial for inferring the underlying synaptic and nonsynaptic mechanisms of brain dysfunction. Focal seizures with secondary generalization are traditionally considered to begin in a limited spatial region and spread to connected areas, which can include both pathological and normal brain tissue. The mechanisms underlying this spread are important to our understanding of seizures and to improve therapies for surgical intervention. Here we study the properties of seizure recruitment- how electrical brain activity transitions to large voltage fluctuations characteristic of spike-and-wave seizures. We do so using invasive subdural electrode arrays from a population of 16 patients with pharmacoresistant epilepsy. We find an average delay of $\sim 30 \mathrm{~s}$ for a broad area of cortex $(8 \times 8 \mathrm{~cm})$ to be recruited into the seizure, at an estimated speed of $\sim 4 \mathrm{~mm} / \mathrm{s}$. The spatiotemporal characteristics of recruitment reveal two categories of patients: one in which seizure recruitment of neighboring cortical regions follows a spatially organized pattern consistent from seizure to seizure, and a second group without consistent spatial organization of activity during recruitment. The consistent, organized recruitment correlates with a more regular, compared with small-world, connectivity pattern in simulation and successful surgical treatment of epilepsy. We propose that an improved understanding of how the seizure recruits brain regions into large amplitude voltage fluctuations provides novel information to improve surgical treatment of epilepsy and highlights the slow spread of massive local activity across a vast extent of cortex during seizure.

Key words: epilepsy; focal seizure; intracranial EEG; seizure propagation; seizure spread

\section{Introduction}

Epilepsy is a multiscale disease that impacts $\sim 50$ million people worldwide. Unfortunately, many patients with epilepsy continue to have seizures despite maximal anticonvulsant therapy (Keränen et al., 1988, 1989; Zarrelli et al., 1999; Annegers, 2001). For these patients, regional surgical resection (i.e., removal of the brain region producing the seizure) may reduce or cure seizures, but this procedure remains an option of last resort, as it carries significant risk and is only curative in $40-70 \%$ of neocortical epilepsy cases (Engel et al., 2003; de Tisi et al., 2011). Improved understanding of the complex dynamics that define the seizing cortex and support seizure initiation and spread is required to advance therapeutic management of this disease.

Although epilepsy is a complex disease, resulting from multiple pathologies, seizures manifest with similar clinical and electrical features across a diverse population of patients. For this

\footnotetext{
Received Jan. 5, 2015; revised April 29, 2015; accepted May 17, 2015.

Author contributions: L.-E.M., 0.J.A., S.S.C., and M.A.K. designed research; L.-E.M., O.J.A., K.Q.L., S.S.C., and M.A.K. performed research; L.-E.M. analyzed data; L.-E.M., O.J.A., K.Q.L., S.S.C., and M.A.K. wrote the paper.

This research is supported by National Institute of Neurological Disorders and Stroke Award R01NS072023 (to M.A.K. and S.S.C.) and Grant SNS062092 (to S.S.C.) and by the Epilepsy Foundation Grant 222178 . We thank the patients who participated in this study and the nursing and physician staff. We also thank Jason Naftulin for technical assistance.

The authors declare no competing financial interests.

Correspondence should be addressed to Mark Kramer, Boston University, Department of Mathematics and Statistics, 111 Cummington Mall, Boston, MA 02215. E-mail: mak@bu.edu.

DOI:10.1523/JNEUROSCI.0049-15.2015

Copyright $\odot 2015$ the authors $\quad 0270-6474 / 15 / 359477-14 \$ 15.00 / 0$
}

reason, a seizure is often conceptualized as consisting of distinct and stereotypical dynamic states (Lopes da Silva et al., 2003; Breakspear et al., 2006; Blenkinsop et al., 2012; Kramer et al., 2012; Jirsa et al., 2014). In humans, these states are typically characterized by the observed voltage dynamics, while animal models permit exploration of the biological mechanisms that underlie these states (McCormick and Contreras, 2001; Pinto et al., 2005; Soltesz and Staley, 2011; Nevado-Holgado et al., 2012). Extensive previous studies, using numerous different measures, have provided insight into the rapid, transient interactions that occur between brain regions during seizures (Gotman, 1983, 1987; Lieb et al., 1987; Spencer et al., 1992; Franaszczuk et al., 1994; Schindler et al., 2007; Kramer et al., 2010). However, understanding the dynamic and biophysical mechanisms of ictal states, and the transitions between them, remain primary goals of epilepsy research.

Among these ictal state transitions, the transition from typical pre-ictal low-amplitude brain voltage dynamics to large voltage fluctuations can be very commonly observed at or following onset of secondarily generalized seizures, which begin focally and then spread to encompass large portions of the brain (Lee et al., 2000; Perucca et al., 2014). Because it is so notable and stereotyped, this transition permits a quantitative analysis of its spatiotemporal dynamics. Here we examine the spatial pattern of this neocortical recruitment across the brain surface as observed using intracranial electroencephalographic recordings of spontaneous seizures from a population of patients with epilepsy. We show that, for individual patients, consistent spatial patterns 
Table 1. Patient information

\begin{tabular}{|c|c|c|c|c|c|c|c|c|c|}
\hline Patient & Sex & $\begin{array}{l}\text { Age at } \\
\text { onset/surgery }\end{array}$ & $N$ & Seizure duration (s) & $\begin{array}{l}\text { Mean seizure } \\
\text { interval (h) }\end{array}$ & Etiology & Seizure focus location & $\begin{array}{l}\text { Engel } \\
\text { Score }\end{array}$ & $\begin{array}{l}\text { Follow-up } \\
\text { time (months) }\end{array}$ \\
\hline P1 & $M$ & $3 / 37$ & 3 & $63,60,133$ & 13.67 & Unknown & Temporal & 1 & 32 \\
\hline P2 & $M$ & $19 / 29$ & 4 & $89,48,105,116$ & 5.29 & Cortical dysplasia & Fronto-temporal & 4 & 111 \\
\hline P3 & $\mathrm{F}$ & $15 / 46$ & 5 & $87,92,102,100,112$ & 7.48 & Cortical dysplasia & Temporo-parieto-occipital & 1 & 12 \\
\hline P4 & M & $7 / 22$ & 2 & 86,92 & 11.16 & Cortical dysplasia & Frontal & 3 & 64 \\
\hline P5 & $\mathrm{F}$ & $14 / 28$ & 3 & $330,110,83$ & 8.39 & Encephalitis & Temporal & 2 & 71 \\
\hline P6 & $\mathrm{F}$ & $1 / 28$ & 2 & 123,201 & 2.49 & $\mathrm{MTS}^{a}$ & Temporal & 2 & 54 \\
\hline P7 & M & $21 / 27$ & 2 & 66,42 & 10.55 & MTS & Temporal & 4 & 208 \\
\hline P8 & $\mathrm{F}$ & $4 / 52$ & 5 & $64,79,31,34,24$ & $\mathrm{~N} / \mathrm{A}$ & MTS & Temporal & 1 & 6 \\
\hline P9 & M & $9 / 19$ & 2 & 86,104 & $\mathrm{~N} / \mathrm{A}$ & Cortical dysplasia & Temporal & 1 & 76 \\
\hline P10 & $M$ & $24 / 28$ & 4 & $171,134,231,146$ & 2.15 & Ectopic neurons $^{b}$ & Frontal & 2 & 27 \\
\hline P11 & $M$ & $19 / 31$ & 4 & $33,38,118,165$ & 3.18 & Unknown, but gliosis present & Frontal & 2 & 90 \\
\hline P12 & M & $10 / 32$ & 2 & 142,165 & 0.63 & Cortical dysplasia & Fronto-temporal & 1 & 64 \\
\hline P13 & $\mathrm{F}$ & $18 / 29$ & 4 & $108,130,132,121$ & 1.97 & Unknown & Temporo-parietal & 1 & 45 \\
\hline P14 & M & $1 / 38$ & 1 & 117 & 15.36 & Tuberous sclerosis & Frontal & 1 & 38 \\
\hline P15 & $\mathrm{F}$ & $8 / 34$ & 5 & $25,23,25,19,26$ & 8.83 & Unknown & Temporal & 3 & 35 \\
\hline P16 & M & $18 / 45$ & 2 & 121,101 & 1.45 & Unknown & Temporo-parieto-occipital & 1 & 13 \\
\hline
\end{tabular}

This table summarizes information about the patients used in this study: sex, age at onset and surgery, number of recorded seizures used in this study ( $M$ ), duration of each seizure (in seconds), mean interval between seizures (in hours), etiology, lobe of the seizure focus location, Engel Score, and follow-up time (in months). N/A, Not available; M, male; F, female. ${ }^{a}$ With possible dysplasia as well; ${ }^{b}$ not a clear dysplasia.

emerge as large amplitude activity spreads across the cortex. This cortical recruitment is slow $(\sim 4 \mathrm{~mm} / \mathrm{s})$ and can be spatially organized or disorganized. The spatially organized recruitment correlates with a more regular, compared with small-world, connectivity pattern in simulation, and successful surgical treatment of epilepsy, despite differences in underlying etiology. We propose that understanding cortical recruitment provides additional insight to guide regional surgical resection for epilepsy.

\section{Materials and Methods}

Patient information and recordings. Electrocorticography (ECoG) from 50 seizures (one to five seizures per patient; mean of 3.1) in 16 patients (six women, mean age at surgery of 32 years with a minimum age of 19 years and maximum of 52 years) with long-standing pharmacoresistant complex partial seizures (mean age at onset of 12 years and mean duration of epilepsy of 21 years) were analyzed (Table 1). Multiple etiologies were represented in this patient population including mesial temporal sclerosis (MTS) as diagnosed by history, seizure semiology, and imaging $(n=3)$; cortical dysplastic lesions confirmed with pathology $(n=5)$; and other etiologies $(n=3)$. In five of the patients, the etiologies were unknown. Seizure onset regions were most common in neocortical temporal structures, mesial temporal structures, or a mix of the two $(n=6)$. In five patients, seizures arose from frontal lobe structures (the cingulated gyrus or orbitofrontal regions). In five patients, the seizures arose from a region covering parts of the temporal, parietal, and occipital lobes.

For this study, patients were selected who were admitted for EEG monitoring between 2006 and 2012, and were known to have seizures with focal onset and typical complex partial events with secondary generalization; patients were not chosen to represent any distributions of seizure onset regions. Seizure type was determined by examination of the patient's invasive EEG recording, simultaneously recorded closed-circuit video recordings of the patient's behavior, and clinical history of the patient. Seizures in which consciousness was impaired in any way were considered complex partial seizures (CPS). Seizures that culminated in bilateral tonic, clonic, or tonic-clonic movements and in which all or nearly all channels showed ictal activity were considered to have had secondary generalization. Determination of the seizure onset time was made by observing when intracranial electrodes began to show standard ictal electrographic activity, including low-voltage fast activity or repetitive spike-wave discharges (Perucca et al., 2014). On average, the time interval between seizures was $6 \pm 5 \mathrm{~h}$. We note that the seizure onset may occur in subcortical or cortical regions, and may precede the recruitment of the observed cortex to large voltage fluctuations. The semiology and ECoG recordings of all patients involved focal features at onset. All seizures used in this study were CPS with secondary generalization.
All recordings were performed using a standard clinical recording system (XLTEK; Natus Medical) with a $500 \mathrm{~Hz}$ sampling rate. The reference channel was a strip of electrodes placed outside the dura and facing the skull at a region remote from the other grid and strip electrodes. Subdural electrode arrays were placed to confirm the hypothesized seizure focus and locate epileptogenic tissue in relation to eloquent cortex, thus directing surgical treatment. The decision to implant the electrode targets and the duration of implantation were made entirely on clinical grounds with no input from this research study. For the analysis presented here we focused on the grid of electrodes ( 64 electrodes, $8 \times 8 \mathrm{~cm}$ with $1 \mathrm{~cm}$ spacing), covering the lateral surface of the cortex, to map seizure recruitment across adjacent regions of cortex. All data analyses were performed under approved Institutional Review Board (IRB) protocols monitored by the Massachusetts General Hospital and Boston University IRBs according to NIH guidelines.

Anatomical figures. To create anatomical representations of electrode placement and ictal spread (Figs. 1C, 2C, 3A, and Movies 1, 2), we used FreeSurfer (Dale et al., 1999) to reconstruct a 3D model of the cortical surface of the patient using preoperative high-resolution MRI data. We then coregistered these MRI data with a postoperative CT scan showing the location of the intracranial electrodes to obtain the coordinates of electrodes in the space of the reconstructed 3D model of the cortex. These procedures are described previously (Dykstra et al., 2012).

Estimation of recruitment times and spatial organization. To characterize how the large voltage fluctuations of seizure spread across the cortical surface, we analyzed the data as follows. First, we excluded intervals of data with nonphysiological artifacts (e.g., intervals of amplifier saturation or extremely large amplitude and short duration outliers); on average $8 \pm 6 \%$ of the seizure duration was omitted from each channel across all patients and seizures. Then, we filtered the data (third-order Butterworth, zero-phase digital filtering) from 0.5 to $249 \mathrm{~Hz}$ and notch filtered the data (third-order Butterworth, zero-phase digital filtering) at 60, 120, and $180 \mathrm{~Hz}$. Next, we computed the average reference of the filtered data and subtracted it from each channel (Towle et al., 1999). Finally, to extract a smooth profile of ictal recruitment representing the intensity of the voltage fluctuations, we computed the time-dependent standard deviation estimate for each channel by dividing the ECoG data into $4 \mathrm{~s}$ windows with $3.9 \mathrm{~s}$ overlap, beginning $20 \mathrm{~s}$ before seizure onset and ending $20 \mathrm{~s}$ after seizure termination, and computing the standard deviation of the signal within each window. As the variance of a weak sense stationary signal is equivalent to its power spectral density integrated over all frequencies, computing the standard deviation is equivalent to measuring the square root of the total power ("root total power"; abbreviated as RTP in this study) in each $4 \mathrm{~s}$ window. We refer to the frequency domain representation of this measure to aid interpretation of the re- 
sults. We note that the RTP measure is similar to the energy defined previously (Litt et al., 2001), but does not depend on the signal mean and is less sensitive to large values because of the square root operation present in the computation. Repeating the analyses using the energy instead of the RTP, or using a smaller (1.25 s) window, leads to qualitatively similar results (data not shown), suggesting that the approach used here is resilient to these changes.

To estimate how the recruitment spreads across the cortical surface, we computed the cross-correlation $r_{i, j}$ between the ECoG RTP of channels $i$ and $j$, and determined the lag of maximum correlation $\tilde{L}_{i, j}$ :

$r_{i, j}(\tau)=\left\{\begin{array}{cc}\sum_{t=0}^{N_{s}+\tau \mid-1} \frac{R \mathrm{~T} P_{i}(t+\tau)-\mu_{i}}{\sigma_{i}} \cdot \frac{R \mathrm{TP} P_{j}(t)-\mu_{j}}{\sigma_{j}} & \tau \geq 0 \\ r_{j, i}(-\tau) & \tau<0\end{array}\right.$

$\tilde{L}_{i j}=\underset{\tau}{\operatorname{argmax}}\left(r_{i, j}(\tau)\right)$.

In the above expression, $N_{s}$ is the number of samples recorded for a seizure and $\mu_{i}$ and $\sigma_{i}$ are the sample mean and sample standard deviation respectively, of the RTP for channel $i$. We note that the existence of a delay between two channels is consistent with a causal relationship, but we conservatively do not interpret these associations as causal. The resulting lags of maximal correlation between all pairs of channels are stored in the matrix $\tilde{L}$; in this matrix, row $i$ corresponds to the lag of maximum correlation between channel $i$ and all other channels. Theoretically any row could be used as an estimate of the delay between channels. However, to reduce the impact of noise and improve the estimates of the delays, we combined the lags across all rows in the following way. We chose the first channel (channel 1) as an arbitrary time reference by shifting the lags in matrix $\tilde{L}$ so that each row represented the lag between channel 1 and all other channels (i.e., each row had a different estimate of the same lags). Then we used the median of column as an estimate of the delay between channel 1 and $j$. To reduce the influence of poorly correlated pairs of channels on the median, we excluded lags corresponding to cross-correlations below the average of maximum cross-correlations between all pairs of channels. Finally we sorted the channels based on their relative delays to obtain the order of recruitment. We measured the recruitment time $T_{j}$ of channel $j$ as the delay between the first recruited channel (according to the resulting ordering) and channel $j$, and the total recruitment time as the delay between the first recruited channel and the last recruited channel. To mitigate the impact of channels recruited much earlier or later than the main recruitment event, we excluded the recruited channels with a delay larger than 3 standard deviations from the mean of delays (average number of channels discarded per seizure is 0.57 , maximum number is 5 ).

To characterize the maximum voltage fluctuations during seizure (referred to as voltage amplitude in the results), we computed for each channel the ratio of the differences between its maximum voltage minus minimum voltage during the seizure and during the interictal period (estimated over the $20 \mathrm{~s}$ before and after the seizure). For each seizure, we then averaged this ratio across channels. To quantify the local relation between channels, we computed the local correlation with grid neighbors for each seizure. To compute this measure, we first determined over the entire seizure the maximum cross-correlation over all lags of the RTP between each electrode and its four adjacent neighbors and then average these four values. We then average these results over all electrodes, for each patient and seizure.

To study the spatial organization of ictal recruitment, we compute a recruitment map. The recruitment map is a square matrix with each element corresponding to a location on the 8-by-8 electrode grid, and the value of each element equal to the recruitment time $T_{j}$ of channel $j$ (i.e., the delay between the first recruited ECoG grid channel determined through the ordering procedure described above and channel $j$ ). In other words, the recruitment map is a two-dimensional representation of the ECoG grid structure, where each electrode is assigned the value equal to its relative recruitment time compared with the first recruited channel. To characterize the spatial organization of the recruitment map we compute the Moran's Index (Moran, 1950), which is a measure of spatial autocorrelation. This index varies between -1 and 1 : a value closer to 1 indicates that channels with similar recruitment times are spatially close. A value equal to 0 indicates that the distribution of recruitment times over the grid is random. A value close to -1 is the result of spatial dispersion of the delays (e.g., early and late recruitment times are mixed together like black and white squares on a chess board). The mathematical formulation of Moran's Index is as follows:

$$
I=\frac{N_{c}}{\sum_{i} \sum_{j} w_{i j}} \frac{\sum_{i} \sum_{j} w_{i j}\left(T_{i}-\bar{T}\right)\left(T_{j}-\bar{T}\right)}{\sum_{i}\left(T_{i}-\bar{T}\right)^{2}},
$$

where $N_{c}$ is the number of channels, $T_{i}$ is the recruitment time of channel $i, \bar{T}$ is the mean recruitment time, and $w_{i j}$ is a matrix of weights chosen to represent the spatial relation between channels. Here we use a weight of 1 if two channels are adjacent on the electrode grid (the four neighborsup, down, left, and right- of a chosen channel), and a weight of 0 otherwise. Finally, we quantified the reproducibility of the spatial pattern obtained for each patient's seizures by measuring the correlation between the recruitment maps for all pairs of seizures for that patient.

To assess the uncertainty of the measured lags between channels and other measures dependent on these lags, we used Monte Carlo simulations based on a bootstrap method adapted to time series (Peterson et al., 2004). For each Monte Carlo realization, this approach has three steps: (1) selection of a random subset of the RTP time series for each channel, (2) addition of noise for each selection, and (3) estimation of the lags between channels. The selection strategy picks $M$ data points with replacement among the RTP time series and counts redundant selections C. $M$ is chosen to equal the number of points in the RTP time series. For each selected sample (i.e., data point) at time $t_{s}$, the added noise follows a Normal distribution of mean 0 and standard deviation $\left(1 / \sqrt{C\left(t_{s}\right)}\right) \cdot \sigma_{R T P}\left(t_{s}\right)$ taking into account the sample redundancy and the standard error of the RTP estimate $\sigma_{R T P}\left(t_{s}\right)$. Since we computed the RTP using the timedependent standard deviation of the voltage, the standard error of the RTP can be approximated by $\sigma_{R T P}\left(t_{s}\right)=R T P\left(t_{s}\right) / \sqrt{2(N-1)}$ where $N$ is the number of samples within the $4 \mathrm{~s}$ moving window (Harding et al., 2014). We computed 1000 Monte Carlo realizations to create the distributions of each measure from which we estimated their respective means and variances. Using this approach, we found that the uncertainty (i.e., standard deviation) of the lags measured between channels using the cross-correlation varies from 0.11 to $3.31 \mathrm{~s}$.

Statistical analysis. We report seizure characteristics by first consolidating the measure across seizures for a patient using a weighted average. We use as weights the inverse of the variance of measurements estimated through Monte Carlo simulations (see previous section), so that seizures with less reliable estimation have less influence on the patient average. We then compute a grand mean across patients. In one case (as noted below), we use a robust estimation of the correlation (noted here as $r_{\text {robust }}$ ) that is less sensitive to the effect from potential outliers (Mosteller and Tukey, 1977). Results in the text and in bar plots represent the estimated grand mean \pm standard deviation of the described statistics, computed across patients. We estimate correlation between several seizure characteristics and determine the significance of these correlations using a threshold of $\alpha=0.05$. We test the existence of two groups of patients based on the properties of their recruitment maps using standard ANOVA.

Simulation of the influence of network connectivity on recruitment dynamics. To study the impact of network connectivity on recruitment, we used a cellular automaton model (Wolfram, 2002). The model is defined as a single-layer network of units (i.e., cells) with excitatory symmetric bidirectional connectivity. We consider each cell as representing the activity of a macroscale brain region beneath an electrode of the ECoG grid. We simulated the activity of grids of 10 -by-10 cells, but studied the activity of only the inner 8 -by- 8 cells to produce recruitment maps with the same resolution as the in vivo data, and reduce edge effects. 
A
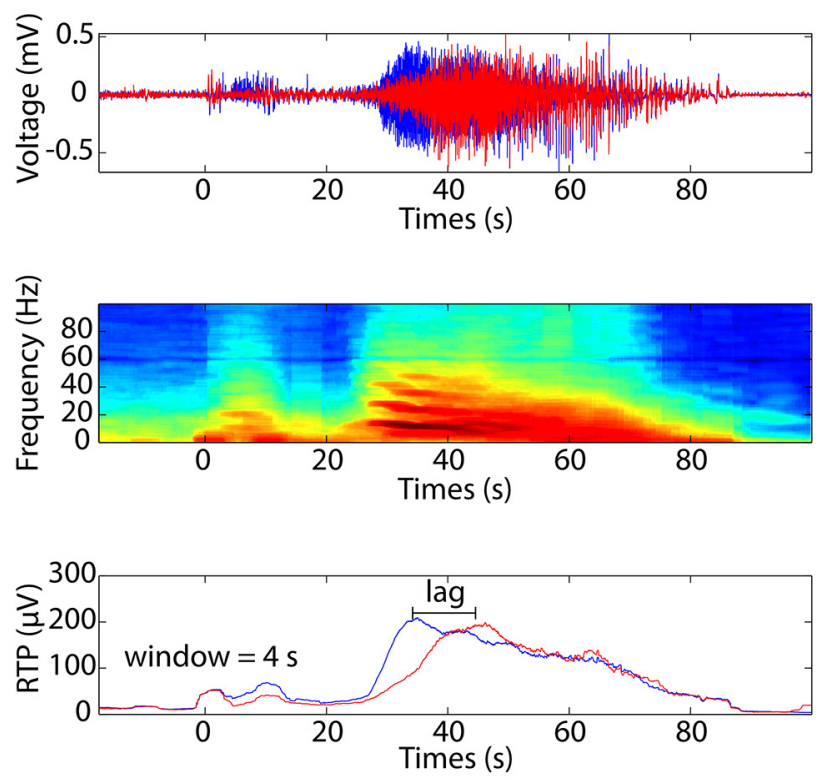

B

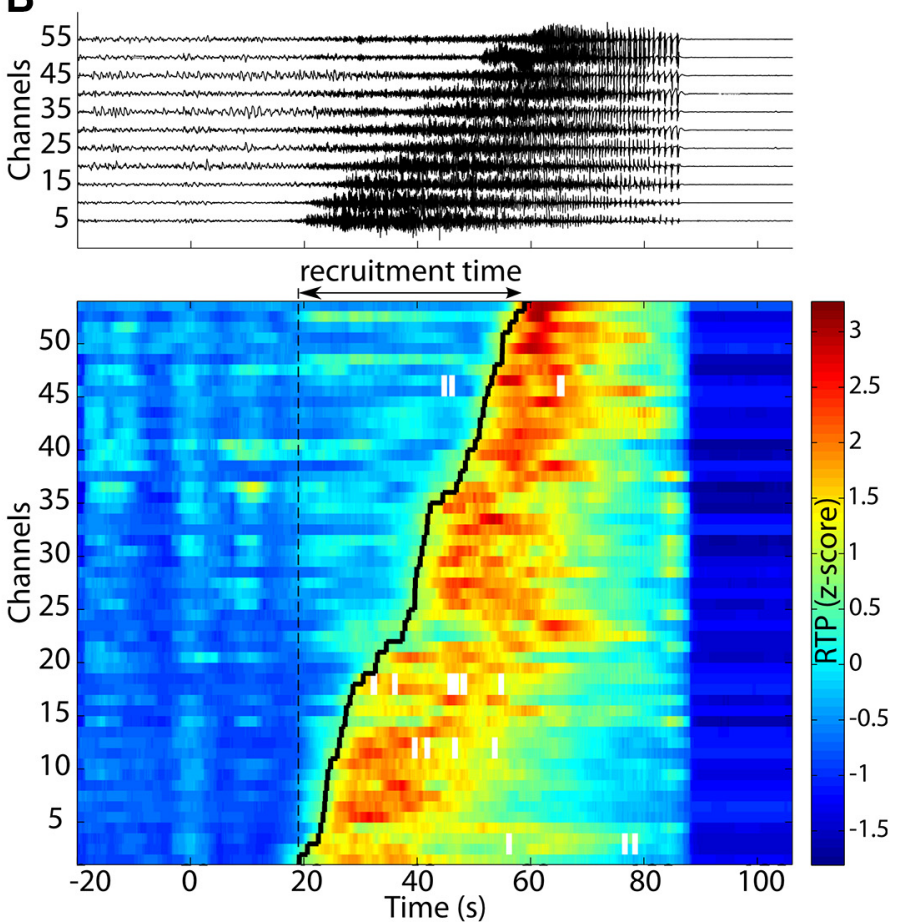

C
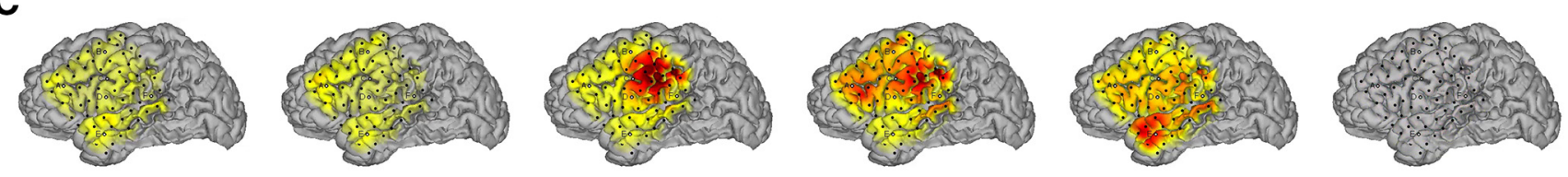

$-10$

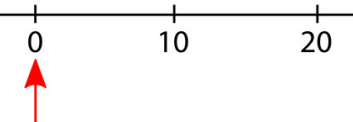

30

40

50

60

70

80

90

Seizure onset

Seizure end

Figure 1. Smooth and slow recruitment of cortical regions after focal seizure onset. $A$, Illustration of channel recruitment analysis procedure. Channel recruitment is measured using the moving RTP of each channel. Top, Voltage traces of two ECOG channels during a seizure (seizure onset at time 0 s and termination at time $89 \mathrm{~s}$ ). The large amplitude oscillations appear first in the blue channel. Center, The power spectrum of the blue channel reveals the characteristic slowing of rhythmic activity during the seizure. Bottom, RTP for both channels computed over a $4 \mathrm{~s}$ window. We focus here on the prominent increase of activity (i.e., recruitment) of each channel and the lag between the initiations of these recruitments of each channel. $\boldsymbol{B}$, Multichannel ordering based on the lag of maximum cross-correlation computed from the RTP. This example is based on seizure 1 of P4. Top, Example of 11 channels (normalized voltage so that each channel has the same maximum amplitude) ordered using the lags. Bottom, Ordered z-scored RTP for all channels of the same seizure. Computing the lags between all channels allows an ordering of the channels and an estimate of the recruitment time ( $\sim 40 \mathrm{sin}$ this example). The black line ("recruitment front") follows the recruitment times of the channels during the seizure. $C$, Time course of the recruitment during seizure 1 of P4 (see $\boldsymbol{B}$ ). Channel recruitment is represented here by coloring the surface of the brain with Gaussian profiles centered at the position of electrodes. Warm colors indicate that channels are recruited into high-amplitude fluctuations. In this example, the recruitment starts after seizure onset (delay of $30 \mathrm{~s}$ ) at the middle-right side of the grid, then spreads to the upper part of the grid and finally to the lower left part.

Connections between cells were of two types: a regular network structure with neighbor-to-neighbor only connectivity (eight neighbors per cell) or a small-world network structure (Watts et al., 1998; Netoff et al., 2004) where a limited number of connections are randomly changed from neighbor-to-neighbor to anywhere on the simulated 10-by-10 grid. In our simulations we chose a rewiring probability of 0.08 for the smallworld networks, so that on average 32 of 400 bidirectional connections were changed.

There are three rules governing the dynamics of the cellular automaton. (1) A cell can be either nonrecruited (value of 0 ) or recruited (value of 1). (2) For each cell $i$ the change from nonrecruited to recruited can occur at each time step depending on the activity of its connected cells, according to $c_{i}=B\left(1, g \cdot \sum_{j} w_{i j} \cdot c_{j}\right)$, where $c_{i}$ is the activity of cell $i, g$ is a gain factor ( $g=0.05$ in our simulation), $w_{i j}=\{0,1 / 8\}$ is the connectivity weight between cell $i$ and $j$, and $B$ is a binomial distribution. (3) Once recruited, a cell remains recruited until the end of the simulation, which occurs once all of the cells have been recruited.

In our simulation, a patient was represented by a given connectivity matrix of the cellular automaton (either regular or small world) and a recruitment seed defined as the first cell of the automaton to be recruited. For each patient, four seizures were simulated with the same recruitment seed. We simulated a population of 32 patients with different seeds uniformly distributed over the inner $8 \times 8$ grid. For each simulation, we computed a recruitment map using the times at which each electrode was recruited (i.e., transitioned from a value of 0 to 1 ). Then, for each patient, we correlated these recruitment maps and computed the Moran's Index. We compared these two measures between the two groups of simulated patients, i.e., the group of simulated patients with a regular network connectivity versus the group of simulated patients with small-world connectivity.

\section{Results}

To characterize the transition to the ictal state of large voltage fluctuations (i.e., "ictal recruitment") occurring at or following seizure onset, we analyzed intracranial EEG data recorded from a population of 16 patients with intractable epilepsy. The seizures from these patients originated from different anatomical loca- 

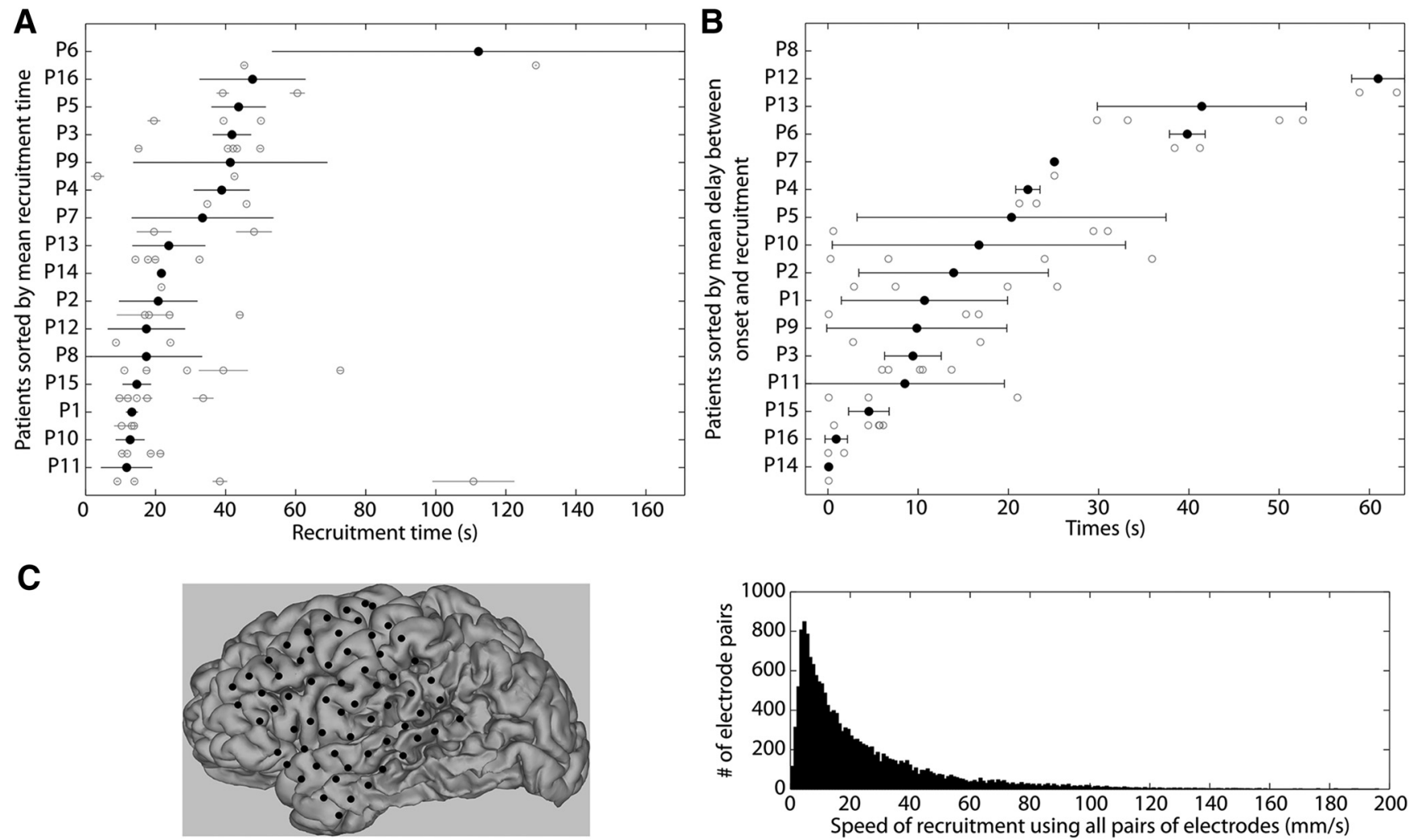

Figure 2. Ictal recruitment spreads over tens of seconds. $A$, Recruitment times for each seizure of each patient. Gray circles and horizontal bars correspond to the recruitment time and uncertainty for individual seizures for each patient (see Materials and Methods). Black circles represent the weighted mean recruitment time \pm standard deviation over all seizures for each patient. Patients are ordered on the vertical axis based on their mean recruitment times. $\boldsymbol{B}$, Delay between seizure onset and recruitment. The delay is measured as time between seizure onset $(t=0 \mathrm{~s})$ and the time at which the RTP of a given seizure exceeds 3 standard deviations above the mean of its pre-ictal RTP. Each gray circle corresponds to one seizure and the black circles with black horizontal bars represent the patient average \pm 1 standard deviation. C Left, Representation of the position of the electrode grid estimated on the folded brain surface for P4. Right, Distributions of recruitment speed between pairs of channels using geodesic distance. These estimates use the combined data of 10 patients for whom we could fully reconstruct brain surface and electrode positions.

tions, and resulted from different underlying pathologies (Table 1). To quantify the extent of the fluctuations, we computed the time-dependent root total power (RTP) of each channel with a $4 \mathrm{~s}$ sliding window (see Materials and Methods). The RTP produced a smooth activation profile in which the transition to recruitment (i.e., the transition to large amplitude activity encompassing increases in several frequency bands) manifested as a slow spatiotemporal evolution of the RTP over the cortical surface (Fig. $1 \mathrm{~A}, \mathrm{C}$ ). We note that the seizure may begin in another location, outside of the observed cortical surface or in a subcortical region; the location of the seizure focus is not investigated here. Instead, we propose to characterize the properties of neocortical recruitment as observed in the surface ECoG and how these properties vary between patients and relate to surgical outcome.

To characterize how the ictal recruitment spreads across the cortical surface, we computed the lag of maximum crosscorrelation of the RTP between all pairs of channels and established a global recruitment order of the channels. Figure $1 B$, top, displays the ECoG from a selection of channels ordered according to recruitment. We note the large voltage fluctuations appearing after seizure onset and spreading over the cortical surface as the recruitment progressed. The same phenomenon appeared in the RTP (Fig. 1B, bottom plot) across all channels. This approach permitted determination of a sequence of recruited channels (called here the recruitment front) from the earliest recruited channel to the last recruited channel, and allowed an assessment of the total recruitment time for the seizure over the ECoG grid (Fig. 1B). In what follows, we analyzed these recruitment times to show (1) that the recruitment of neuronal population activity to the seizure occurred slowly (at a scale of several tens of seconds) over the cortical surface, (2) that the spatial organization of the recruitment divided patients into two populations, and (3) that the degree of spatial organization correlated with surgical outcome.

\section{Ictal recruitment is a slow process}

We estimated the total recruitment time for each seizure as the delay between the first and last recruited channels. The grand mean recruitment time spanned tens of seconds (mean $32 \pm 23 \mathrm{~s}$; Fig. 2A), although a high variability between patients was present (minimum $11 \mathrm{~s}$ for P11, maximum $112 \mathrm{~s}$ for P6). Some patients exhibited consistent recruitment times across seizures (minimum standard deviation of $2 \mathrm{~s}$ for the three seizures of P1), whereas other patients exhibited large variability in recruitment times from seizure to seizure (maximum variability of $59 \mathrm{~s}$ for the two seizures of P6). Across patients, the mean recruitment time was correlated with its variance $\left(r_{\text {robust }}=0.65, p=0.006\right)$, suggesting that patients with longer recruitment times exhibited more variability in those recruitment times from seizure to seizure. This intuitive result could not be assumed a priori, and an inspection of Figure $2 A$ provides examples of patients with low mean recruitment times and high variance (e.g., P8) and high mean recruitment time with low variance (e.g., P3).

Recruitment time was correlated with the seizure duration determined independently by a team of epileptologists $(r=0.29$, 
A

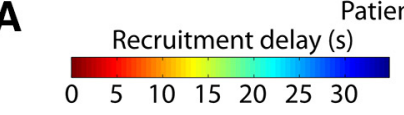

Patient P4
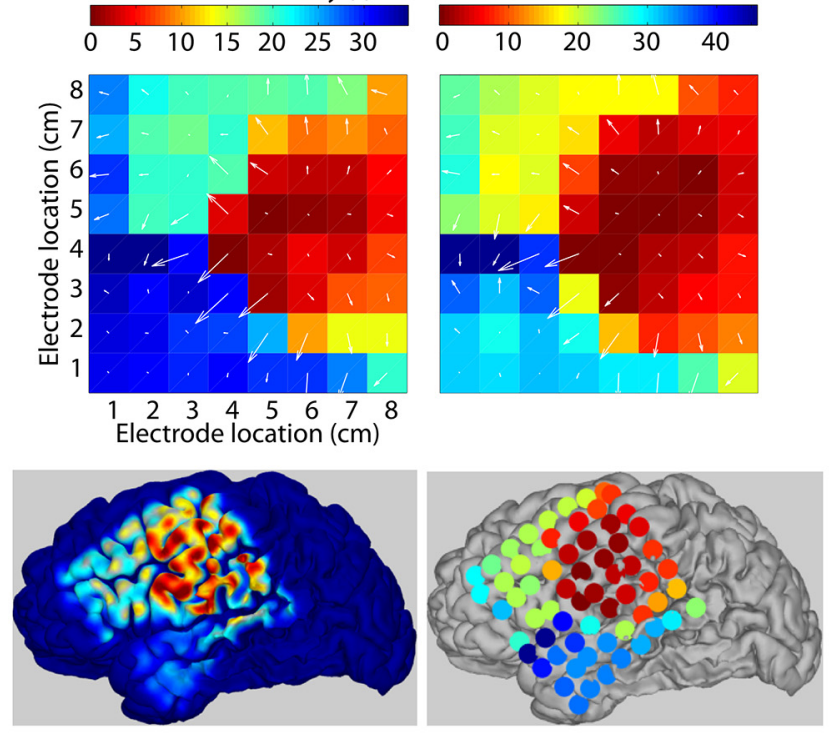

B

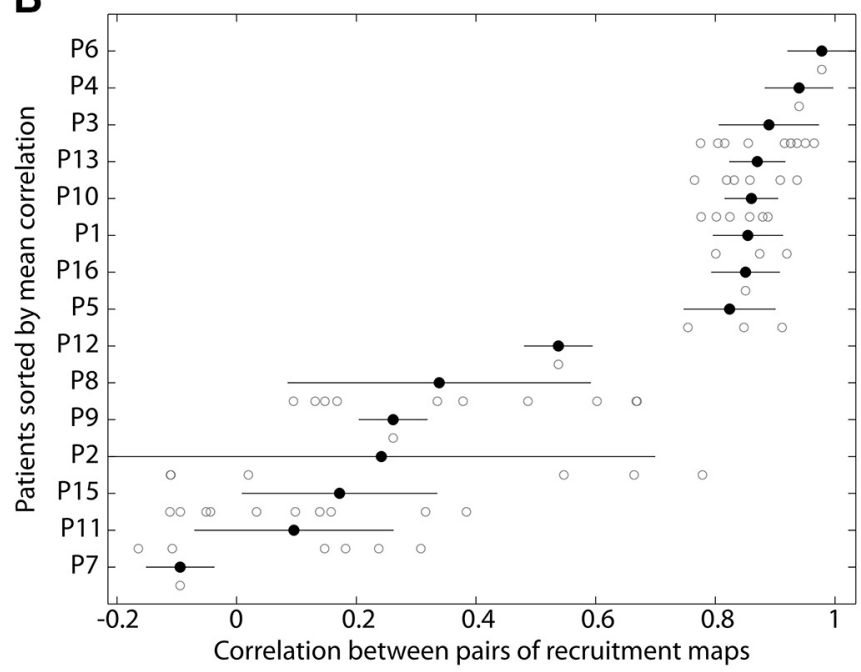

Patient P11

Recruitment delay (s)
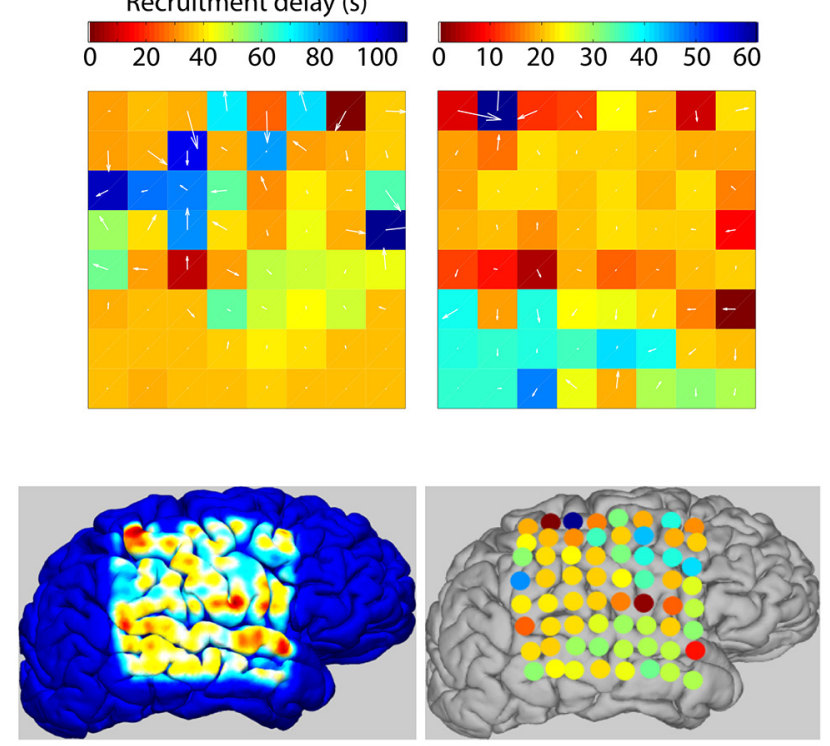

C

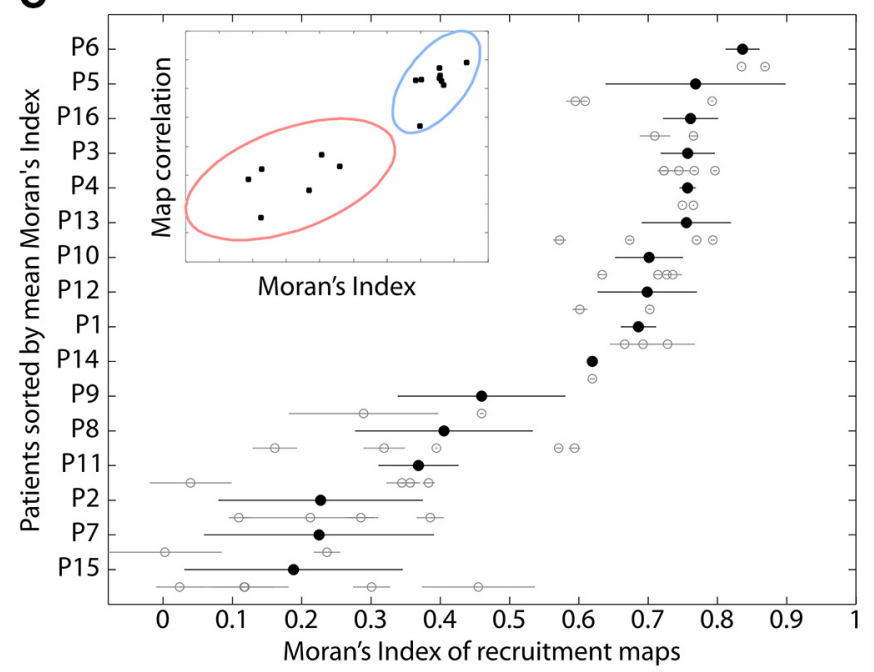

Figure 3. Spatial properties of recruitment maps define two categories of patients. $A$, Example recruitment maps for two seizures of two patients (P4 and P11). The first patient (P4, left) exhibits an organized pattern of recruitment, consistent from seizure to seizure, as opposed to the second patient (P11, right). White arrows represent the gradient of recruitment times from early to late times (i.e., from warm to cool colors). For these two patients, the bottom pictures represent the average recruitment map projected on the brain's surface using two approaches, either by coloring the surface of the brain with Gaussian profiles centered at the position of electrodes and with decreasing color intensities with the distance to the electrode, or by plotting colored disks above the position of each electrode. $\boldsymbol{B}$, Pearson's correlation between pairs of recruitment maps for each patient. Each gray circle corresponds to a pair of seizures. Black circles and black horizontal bars represent the mean \pm standard deviation of the correlation for a patient. Patients are ordered on the vertical axis based on their mean correlation value. C, Spatial autocorrelation of the recruitment maps measured using Moran's Index (see Materials and Methods). Patients are ordered based on their mean Moran's Index. Each gray circle and gray horizontal bar corresponds to the Moran's Index of one seizure with its uncertainty, and the black circles with black horizontal bars represent the weighted mean \pm 1 standard deviation of the Moran's Index for each patient. Inset, Relation between Moran's Index and correlation between pairs of recruitment maps (see $\boldsymbol{B}$ ). The ellipses represent the areas within 3 standard deviations around the centers of the two clusters of patients obtained using the Gaussian mixture model: one group of patients with large Moran's Index and correlation between recruitment maps (blue ellipse) and one group with a low value for these two measures (red ellipse).

$p=0.04$, using all seizures without patient average). We note that the recruitment of all channels to the large fluctuations of seizure represents a subinterval of the entire seizure, and necessarily occurs between seizure onset and termination. As expected, the recruitment process, even if spanning tens of seconds, was limited to a subinterval of the entire seizure (total seizure duration $2.3 \pm$ 0.4 times longer than recruitment, estimated with a least-squares fit). Moreover, the observed neocortical recruitment as measured here on the surface ECoG grid, which has a limited extent, did not start exactly at the time of the seizure onset, as determined through inspection of surface and depth recordings by an epilep- tologist. For example, the seizure in Figure 1 exhibits a large increase in amplitude starting $\sim 25 \mathrm{~s}$ after the seizure onset. Defining the recruitment start as the time when the ictal RTP becomes larger than 3 standard deviations above the mean pre-ictal RTP, we found the mean delay between seizure onset and recruitment start to be $22 \pm 17 \mathrm{~s}$ (Fig. $2 B$ ). This delay is expected as the seizure propagates from an onset location (perhaps in a subcortical region) to the cortical surface observed in the ECoG. We found no significant differences in this delay between seizures with different onset locations $\left(F_{(2,13)}=0.5, p=0.6\right.$, see Table 1$)$ or resulting from different etiologies $\left(F_{(3,12)}=0.8, p=0.5\right)$. 

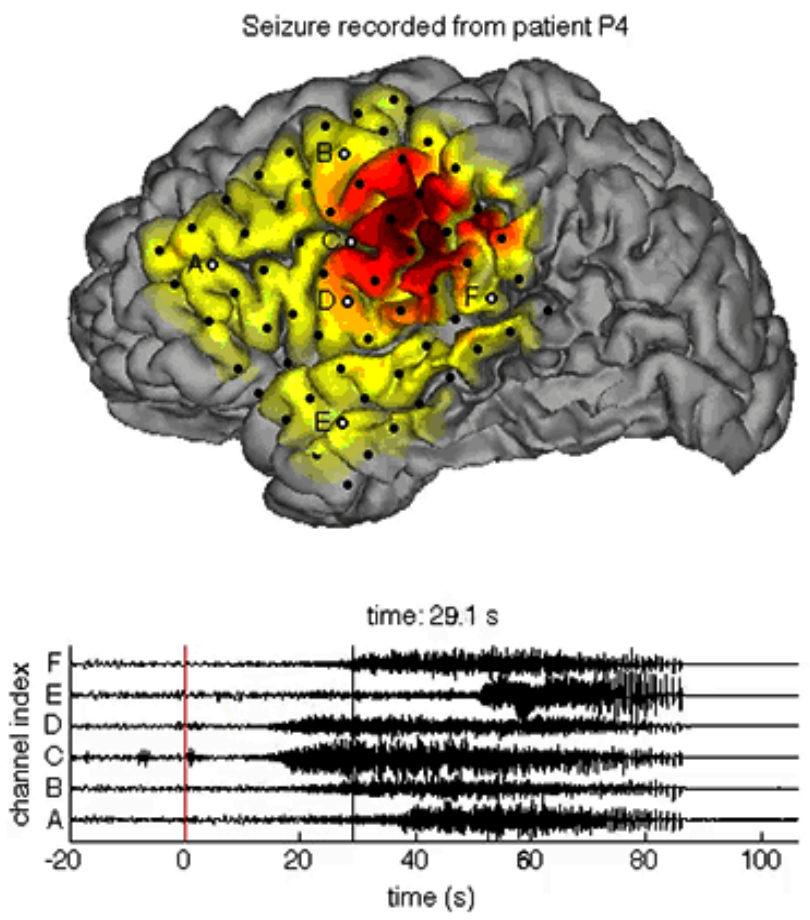

Movie 1. Movie showing the recruitment dynamics for a patient with a spatially organized recruitment pattern (P4). The speed of the movie is approximately eight times as fast as real time. The color for each channel at a given time represents the moving RTP computed over a $4 \mathrm{~s}$ time window centered at this time (see also Fig. 10. Seizure onset is marked by a red vertical bar (at time 0 s) on the bottom plot, where the channel indices $(\mathrm{A}-\mathrm{F})$ are indicated in the anatomical figure above.

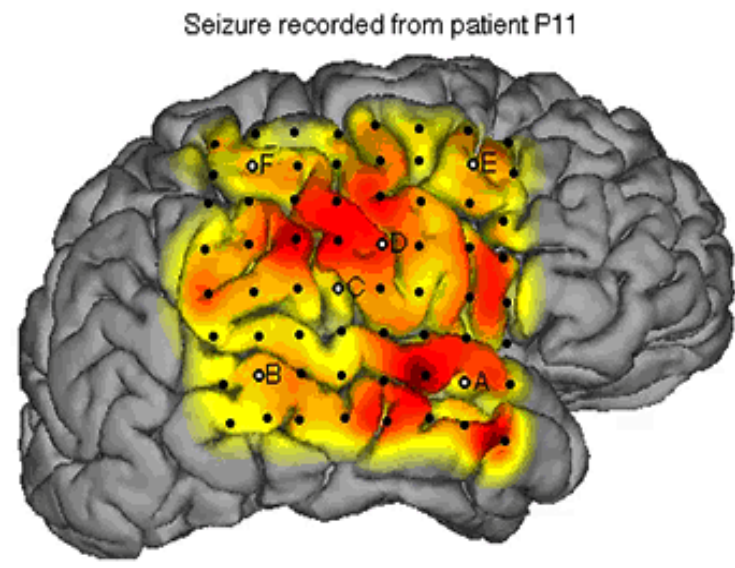

time:29.1 s

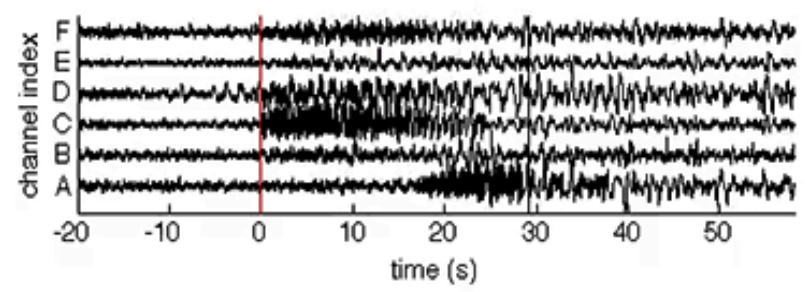

Movie 2. Movie showing the recruitment dynamics for a patient with a poorly organized recruitment pattern (P11). Movie details are provided in the Movie 1 caption.

We estimated the spatial speed of recruitment by determining the ratio of distance over delay between all pairs of channels. Using the electrode coordinates from each patient's reconstructed 3D model of cortex (Fig. 2C, left), we computed the geodesic distance between each pair of channels, which is the shortest distance along the surface of the brain. We note that this estimation of speed has two potential caveats: (1) the geodesic distance does not represent the real distance in terms of neural pathways (but is a better estimation than the distance between ECoG grid electrodes) and (2) the delays between pairs of channels are not representative of a causal influence, and so a measure of delay only suggests that the seizure could spread causally from one channel to another. We found a speed of recruitment with a mode of $4.3 \mathrm{~mm} / \mathrm{s}$ (full-width at half-maximum [2.1, 12.3] $\mathrm{mm} / \mathrm{s}$; Fig. $2 C$, right). When we averaged the speed estimation across seizures for each patient, and then averaged these results across patients, we found a grand mean of $8 \pm 4 \mathrm{~mm} / \mathrm{s}$ (minimum $4 \mathrm{~mm} / \mathrm{s}$, maximum $20 \mathrm{~mm} / \mathrm{s}$ ).

\section{The spatial organization of recruitment varies among} patients

We next examined how seizure recruitment was organized over the neocortical surface. Figure $3 A$ shows two illustrative examples of seizure recruitment maps (i.e., the spatial representations on the 8-by-8 ECoG grid of the recruitment times of each channel). In one case (P4), the maps from two seizures were similar; for this patient, a stereotyped spatial pattern of recruitment occurred during seizure. Moreover, visual inspection suggests that the pattern is spatially organized: early recruitment times (i.e., warm colors in Fig. 3A) are adjacent, and late recruitment times (i.e., cool colors in Fig. 3A) are adjacent. These recruitment maps are consistent with the emergence of large amplitude activity such as spike-and-wave discharges in a spatially limited area of the cortex (potentially originating from subcortical structures, not directly resolved in the ECoG activity) and the subsequent slow spread of this activity (see Fig. $1 C$ and Movie 1 for the full spatiotemporal dynamics of the RTP during one seizure of P4). The recruitment maps for another patient (P11) exhibited quite different characteristics: in this case, the recruitment maps were not consistent from seizure to seizure, and no clear spatial organization was present during the recruitment, which started in several spatially separate channels, and then subsequently jumped to the temporal lobe (see Movie 2 for one seizure of P11).

To assess the spatial organization of the recruitment maps, we considered two quantities: the similarity of the recruitment patterns from seizure to seizure in each patient (using the correlation; Fig. $3 B$ ), and the spatial organization of the recruitment maps for each seizure (using the Moran's Index, a measure of spatial autocorrelation; Fig. 3C). From the correlation analysis (Fig. 3B), visual inspection suggests two groups of patients: one group with similar ictal recruitment patterns from seizure to seizure and another group with more variable recruitment patterns from seizure to seizure. Analysis of the spatial organization of the recruitment maps for each patient (Fig. $3 C$ ) also revealed two groups: one group with strong spatial organization and another group with weaker spatial organization. Using a Gaussian mixture model with two components, we clustered the patients using the recruitment map correlation and the Moran's Index. We used a clustering index (Hubert statistic) to reject the null hypothesis that these patient characteristics were randomly distributed $(p=$ $0.001)$. We note that the correlation between seizure duration and Moran's Index was strong $(r=0.74, p=0.001)$; in other words, longer seizures were associated with increased spatial organization of the recruitment map, whereas seizures of shorter duration tended to exhibit decreased spatial organization. We also note that the similarity of recruitment patterns from seizure to seizure (Fig. 3B), and the degree of spatial organization within 
each seizure (Fig. 3C), were strongly correlated ( $r=0.94, p=2 \times$ $10^{-7}$; Fig. $3 C$, inset). This result indicates that a patient with a spatially organized recruitment pattern is more likely to have similar recruitment patterns repeated from seizure to seizure. We note that most patients with a high Moran's Index possessed seizure activity similar to P4, consisting of large amplitude oscillations and an abrupt transition to low-amplitude activity at seizure termination, while the patterns of voltage fluctuations in the group of patients with low Moran's Index were more varied.

A potential concern is that the lower spatial organization in one group of patients could result from a late propagation effect caused, for example, by a larger distance between the seizure focus and the surface ECoG grid. However, we did not find evidence for a relationship between this delay (i.e., the delay between seizure onset and the initial recruitment at the cortical surface) and spatial organization of recruitment. We note that for some patients with high spatial organization the delay between seizure onset and recruitment on the ECoG grid was long (e.g., $\sim 20$ s for patient P4; Fig. 2B, Movie 1), while for other patients with low spatial organization, the recruitment manifests on the ECoG grid quickly after seizure onset (e.g., P11; Fig. 2B, Movie 2). In addition, we did not find a significant correlation between the delay from onset to cortical recruitment (Fig. 2B) and Moran's Index $(p=0.26)$.

\section{The spatial organization of recruitment is related to seizure amplitude}

We next examined how the amplitude of seizure activity related to the organization of ictal recruitment. To do so, we first divided the patient population into two groups based on the spatial organization of ictal recruitment: one group with low spatial organization and another with high spatial organization. These two groups correspond to patients with low and high Moran's Index, respectively, as shown in Figure 3C. The amplitude of ECoG activity during seizure (normalized by the interictal amplitude, see Materials and Methods) of patients with higher Moran's Index was significantly higher than the amplitudes of the patients with lower Moran's Index (Fig. $4 A ; F_{(1,14)}=7.1, p=0.02$ ). Without dividing the patients into two groups, we also found a strong correlation between the Moran's Index and amplitude $(r=0.65$, $p=0.006$ ).

We further explored the relation between amplitude and recruitment across different frequency bands using the same set of ECoG data, band filtered at delta $(1-4 \mathrm{~Hz})$, theta $(4-8 \mathrm{~Hz})$, alpha $(8-13 \mathrm{~Hz})$, beta $(13-30 \mathrm{~Hz})$, and gamma $(30-100 \mathrm{~Hz})$ ranges. In doing so, we preserved the two groups of patients identified in the broadband analysis (see Fig. $3 \mathrm{C}$ ) and applied the same analysis methods as for the broadband signals. We found that the recruitment time estimated from the band-filtered signals was not significantly different between the band-filtered and broadband activity $\left(F_{(5,10)}=0.34, p=0.89\right)$. We also found significant differences between the amplitudes of the frequency bands $\left(F_{(4,70)}=\right.$ $\left.6, p=4 \times 10^{-4}\right)$. In particular, the alpha, beta, and gamma bands of patients with high spatial organization had significantly higher amplitudes during seizure compared with the delta band of the same group, and also compared with corresponding bands in patients with poor spatial organization (multiple comparisons with $p<0.01$; Fig. $4 B$ ). Finally, the band-filtered recruitment maps were highly correlated (i.e., had very similar recruitment patterns) with the broadband recruitment maps except for the delta band (average correlation for delta: $0.4 \pm 0.3$, average correlation for other bands pooled together: $0.8 \pm 0.2$ ). Overall these results indicate a broadband effect of the recruitment consistent with large amplitude, nonsinusoidal, discharges in the ECoG data, which are common in these types of seizure. In this way, the increased amplitude of ECoG activity in patients with higher spatial organization is representative of a wideband power increase, rather than increased power of a specific neuronal rhythm.

\section{Network characteristics influence recruitment dynamics in the data and in a simulated model of recruitment}

To investigate the relationship between the amplitude of ECoG activity and the spatial organization of ictal recruitment, we measured the local correlation between grid neighbors (see Materials and Methods), which quantifies the mutual influence of each channel with the adjacent channels on the ECoG grid (Fig. 4C). We found that patients with higher spatial organization in the recruitment maps exhibited significantly larger local correlation of the ECoG activity between neighboring channels (Fig. 4C; $\left.F_{(1,14)}=14, p=0.002\right)$. We interpret these results as supporting the hypothesis that, in the case of a seizure with large voltage fluctuations, ictal activity acts as a strong driver of neighboring brain regions, resulting in a systematic and spatially consistent recruitment pattern.

To further investigate the spread of recruitment we implemented a model of interconnected brain regions based on cellular automata (Wolfram, 2002). We chose this modeling framework both for its simplicity and for its consistency with the observed ECoG data; in these data, we lack direct observations of the mechanisms responsible for recruitment and could not constrain these mechanisms in a more detailed biophysical model. We therefore chose a model without detailed biophysical mechanisms. Despite its simplicity and limited number of parameters, this modeling approach has proved successful in investigations of complex network dynamics, such as oscillation and fast wave propagation (Traub et al., 1999, 2010; Lewis and Rinzel, 2000). The model is defined as a single-layer network of brain regions (called cells in this framework) with excitatory symmetric bidirectional connectivity (see Materials and Methods). We studied the influence of two types of network connectivity-regular and smallworld — on the recruitment dynamics (Watts et al., 1998; Netoff et al., 2004). Examples of simulated recruitment for these two types of networks are shown in Figure 5A. For these two types of networks, we measured three characteristics representative of the recruitment dynamics: recruitment time, correlation between recruitment maps over multiple simulations with a fixed network connectivity, and Moran's Index (Fig. $5 B-D$ ). We found that the recruitment time was significantly shorter for small-world networks $\left(F_{(1,62)}=26.6, p=3 \times 10^{-6}\right.$; Fig. $\left.5 B\right)$. The faster recruitment in the small-world networks can be explained by the additional long-range connections, which allow the recruitment to "jump" to a nonlocal spatial location and therefore spread more quickly over the entire surface (example in Fig. $5 \mathrm{~A}$, bottom, at time 100 a.u.). This observation is consistent with the results of the spatial measures: the Moran's Index of the recruitment maps $\left(F_{(1,62)}=110.6, p=2 \times 10^{-15}\right.$; Fig. $\left.5 D\right)$ and the correlation between the different recruitment maps for a fixed network $\left(F_{(1,62)}=37.6, p=7 \times 10^{-8}\right.$; Fig. $\left.5 C\right)$ were significantly lower for the small-world networks, indicating a less spatially organized and less consistent recruitment compared with the regular network connectivity. These simulation results capture the differences observed in the two populations of patients. In simulation, the regular network topology supports a slower, more spatially organized and consistent recruitment, compared with the smallworld topology, where long-distance connections support faster recruitment and more spatially variability. We note that, consis- 

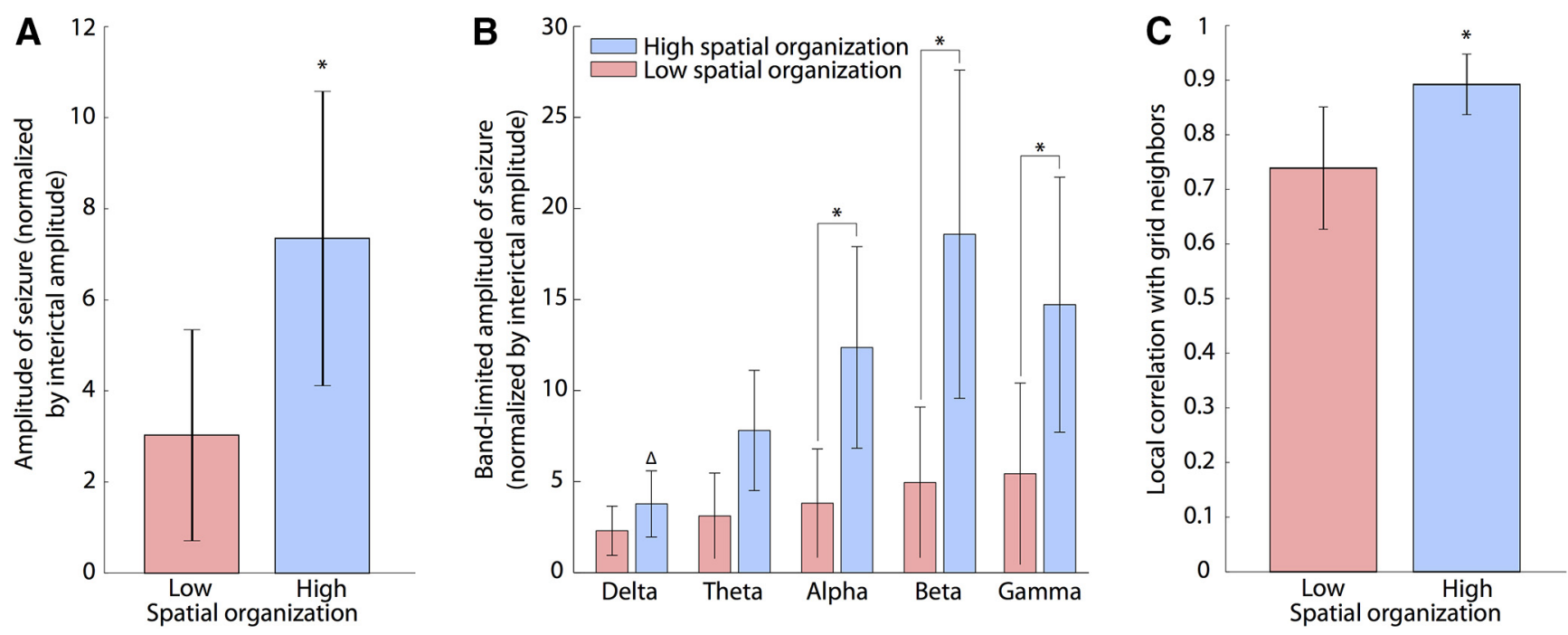

Figure 4. The level of spatial organization of recruitment is modulated by different characteristics of ictal activity. $A$, Relation between Moran's Index and amplitude of seizures (normalized by interictal amplitude) averaged across all channels. There is a significant difference of amplitude (* indicates $p<0.05)$ between the groups of patients with low Moran's Index (red bar) and patients with high Moran's Index (blue bar). $\boldsymbol{B}$, Normalized amplitudes of band-filtered activity during seizures for different frequency bands (delta, theta, alpha, beta, and gamma). We find a significant increase $(p<0.05)$ between alpha, beta, and gamma bands of the high Moran's Index group compared with the delta band of the same group $(\Delta)$ and the corresponding bands in the low Moran's Index group $\left(^{*}\right)$. C, Local correlation structure of the ECoG activity, measured by the mean correlation of one channel to its four neighbors. There is a significant difference of local correlation between the two groups of patients (* indicates $p<0.05$ ).

tent with simulations of the regular network, the patients with more spatially organized and consistent recruitment also showed a trend toward slower recruitment (mean recruitment time $37 \mathrm{~s}$ for patients with high Moran's Index compared with $23 \mathrm{~s}$ for patients with low Moran's Index). However, this difference in recruitment time was not significant for the sample size of patients considered here $\left(F_{(1,14)}=1.23, p=0.28\right)$.

\section{Spatial organization of recruitment correlates with surgical outcome}

We have identified two categories of patients in our data-those with spatially organized recruitment maps and those with spatially disorganized recruitment maps-and explored several factors of ictal activity that may influence this organization. We now consider the relationship between the spatial organization of a patient's recruitment map and the outcome of resective surgery to treat epilepsy. We used the Engel Score (Engel et al., 1993) to quantify the degree of recovery from epilepsy after surgery. It is an ordinal variable ranging from 1 to 4 and indicates that the patient (1) is seizure-free, (2) has rare seizures, (3) has worthwhile improvements, or (4) has no improvements. The mean follow-up time after surgery was $59 \pm 49$ months. We found that the group of patients with higher spatial organization of recruitment had significantly lower Engel Scores (Fig. $6 A ; F_{(1,14)}=7.56$, $p=0.02)$. Alternatively, when estimating an ordinal regression of the Engel Score on the Moran's Index (predictor) we found that the Moran's Index decreased with the Engel Score (proportional odds model with an odds ratio of 123.01, $p=0.046$; Fig. $6 B$ ). These results suggest that a more spatially organized recruitment pattern is likely to be associated with an improved surgical outcome. We also analyzed the relation between seizure amplitude (predictor) and Engel Score and found that the higher amplitude ictal ECoG activity was associated with improved surgical outcome (proportional odds model with an odds ratio of 1.61, $p=$ 0.023; Fig. 6C).

Because of limited samples for each case, we did not characterize the precise shapes of the recruitment maps for different seizure onset locations and etiologies (Table 1). However, the placement of the ECoG grids resulted in recordings of similar cortical regions from patients with different seizure onset locations and etiologies. Yet, we found no significant differences in the spatial organization of the recruitment maps (as measured by the Moran's Index $)$ for different seizure onset locations $\left(F_{(2,13)}=\right.$ $1.5, p=0.27)$ or different etiologies $\left(F_{(3,12)}=0.4, p=0.76\right)$. We also tested the relationship between these two patient variables and the Engel Score and found no significant differences in Engel Score from seizure onset location $\left(F_{(2,13)}=0.2, p=0.81\right)$ or etiology $\left(F_{(3,12)}=0.3, p=0.83\right)$. These results are consistent with the notion that the transition to recruitment evolves similarly in cortex despite differences in seizure onset location and etiology, and that these two factors were not major confounds in the context of this study. We also tested whether the time interval between seizures had any relationship with Moran's Index, and found no significant difference for the interseizure time between patients with higher or lower spatial organization of recruitment $\left(F_{(1,12)}=0.03, p=0.87\right)$. Finally, we compared the mean delay between onset of epilepsy and surgery for the two groups to examine whether the duration of the disorder affected the spatial organization of recruitment. We found that patients with higher spatial organization tended to have been diagnosed with epilepsy for a longer time (mean $25 \pm 13$ years compared with $13 \pm 8$ years, marginally significant, $\left.F_{(1,14)}=3.5, p=0.08\right)$.

\section{Discussion}

How seizure activity spreads throughout the human brain is not fully understood. Here we have used intracranial recordings of seizures from patients with intractable epilepsy to characterize the timing and spatial organization of the recruitment of neocortex to large amplitude activity following the onset of a secondarily generalized seizure. We have shown that recruitment to this dynamic state recorded at the cortical surface was a relatively slow process that occurred over tens of seconds. In addition, the degree of spatial organization of this recruitment was patient dependent: some patients exhibited spatially organized recruitment 

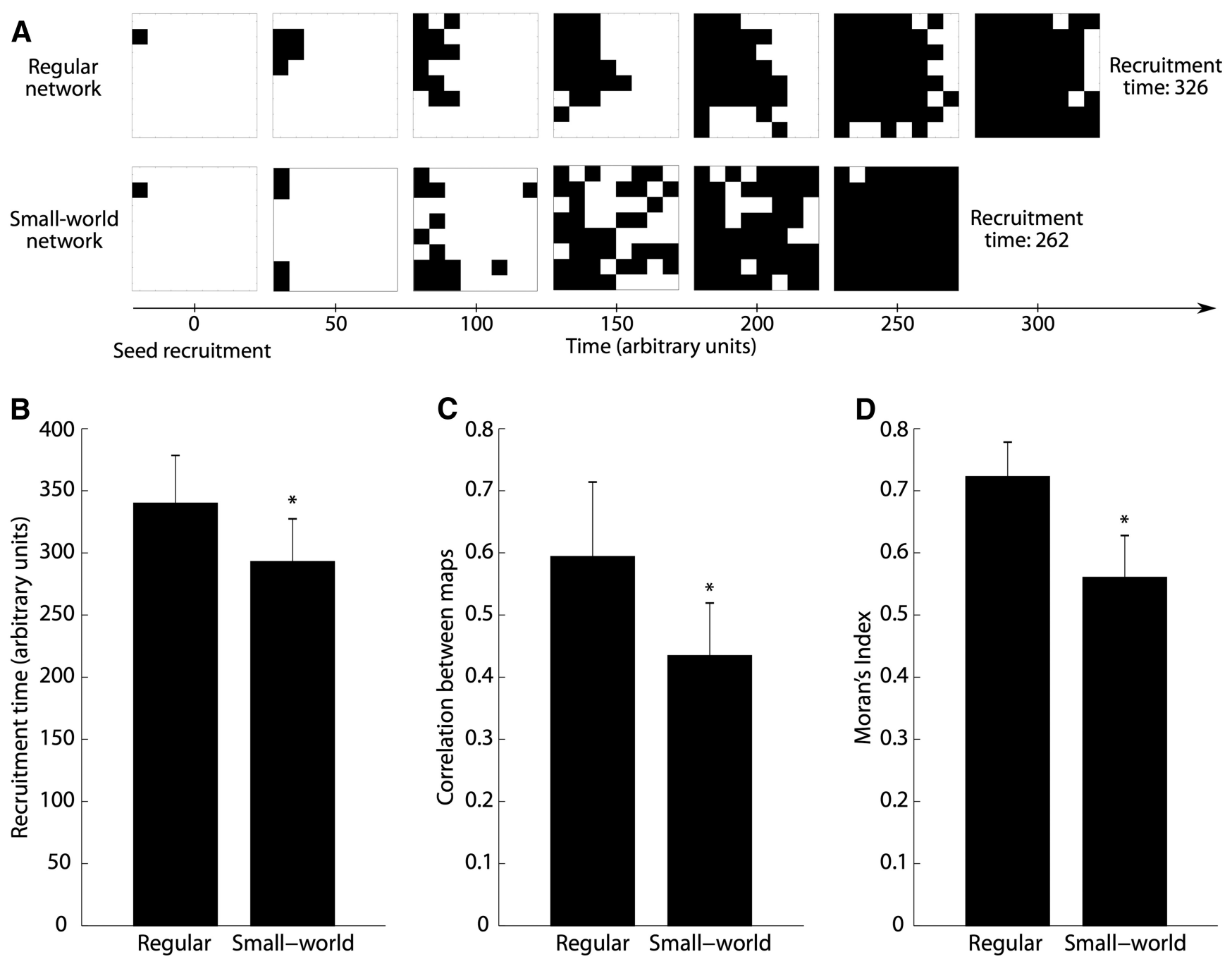

Figure 5. Simulation results using a cellular automaton model indicate an influence of the network connectivity on recruitment. $\boldsymbol{A}$, Simulations of recruitment for two types of network connectivity (top, regular; bottom, small world) using the same seed position. Each 8-by-8 grid represents the cells of the cellular automaton that are recruited (in black) at a given time (every 50 time units). $\boldsymbol{B}$, Simulated recruitment time (a.u.) measured for the regular connectivity and small-world connectivity groups. The recruitment time was significantly shorter for small-world networks $\left(F_{(1,62)}=26.6, p=3 \times 10^{-6}\right)$.C.Correlation between the different recruitment maps for a given network. The map correlation was significantly lower for the small-world networks $\left(F_{(1,62)}=37.6\right.$, $\left.p=7 \times 10^{-8}\right) \cdot \boldsymbol{D}$, Moran's Index of the simulated recruitment maps. We found a lower spatial organization for the group with small-world connectivity $\left(F_{(1,62)}=110.6, p=2 \times 10^{-15}\right)$.

consistent from seizure to seizure, whereas other patients did not. We found that increased seizure amplitude was correlated with a more organized spatial recruitment pattern, and the relationship between the amplitude of activity and its spatial organization was consistent across frequency bands. Moreover we have shown, using patient data and simulations of a relatively simple computational model, that the local network structure had a strong relation with the spatial organization of recruitment. Finally, we showed that the more organized spatial recruitment correlated with successful surgical outcome for these patients. These findings suggest new metrics to consider when evaluating surgical treatment of epilepsy.

\section{Timescale of ictal recruitment}

We measured a mean recruitment delay of $\sim 30 \mathrm{~s}$ for an ECoG grid of $8 \times 8 \mathrm{~cm}$, with a corresponding recruitment speed of $\sim 4$ $\mathrm{mm} / \mathrm{s}$. This result is consistent with the range of estimates for seizure propagation reported in previous studies. In human patients, seizure propagation has been found to exhibit slow dynamics spanning tens of seconds, with propagation speeds varying from 0.2 to $10 \mathrm{~mm} / \mathrm{s}$ (Lieb et al., 1986; Brekelmans et al.,
1995; Blume et al., 2001; Auer et al., 2008; Sonmezturk et al., 2011; Schevon et al., 2012). From in vitro models, the speed of seizure spread varies from 0.1 to $1.34 \mathrm{~mm} / \mathrm{s}$ in a $0 \mathrm{Mg}^{2+}$ model (Wong and Prince, 1990; Holtkamp et al., 2003; Trevelyan et al., 2006 ) to $20-100 \mathrm{~mm} / \mathrm{s}$ in disinhibited neocortical slices (Chervin et al., 1988; Wadman and Gutnick, 1993; Albowitz and Kuhnt, 1995; Pinto et al., 2005; Trevelyan et al., 2006). We note that these characteristics are far slower than the conduction velocities found in brain (e.g., for mossy fibers $300 \mathrm{~mm} / \mathrm{s}$; Andersen et al., 1978), but much faster than observed in migraine and cortical spreading depression ( $3 \mathrm{~mm} / \mathrm{min}$; Eikermann-Haerter and Ayata, 2010). Characterizing the speed of recruitment may help identify mechanisms with appropriate (slow) timescales to support seizure spread.

The variability between these measured speeds in patients may occur for multiple reasons, including differences in quantitative methods and in the spatial scale of the observations. In addition, seizure propagation may depend upon the interval of seizure examined. In this study, we did not strictly examine the propagation of seizure onset, which manifests in multiple ways (Perucca et al., 2014). Instead, we examined the transition to large voltage 

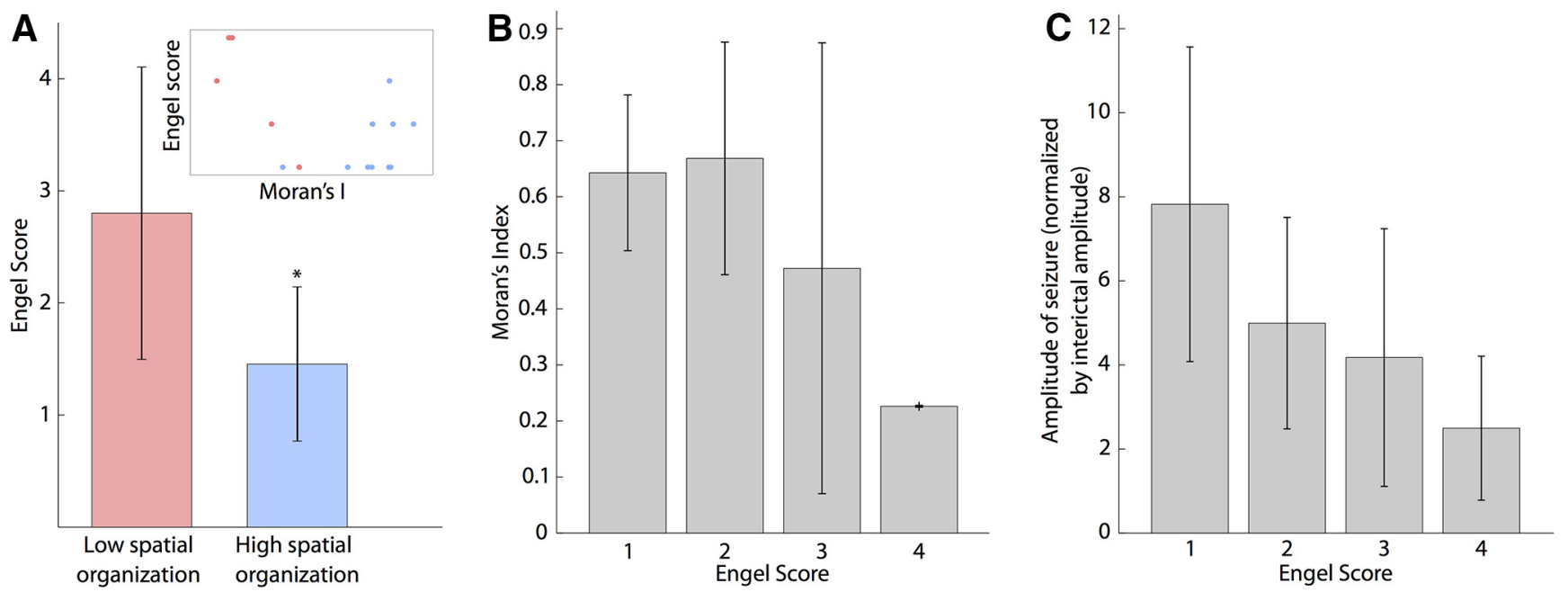

Figure 6. The degree of spatial organization of ictal recruitment and outcome of surgery are linked. $\boldsymbol{A}, \boldsymbol{B}$, Relation between Moran's Index and Engel Score. $\boldsymbol{A}$, There is a significant difference in Engel Score (* indicates $p<0.05$ ) between the groups of patients with low Moran's Index (red bar) and the patients with high Moran's Index (blue bar). Inset, Relation between Moran's Index and Engel Score (each point represents one patient, colored based on the patient's group). $\boldsymbol{B}$, When grouping the patients by outcome of resective surgery (i.e., Engel Score) and using an ordinal regression with the Moran's Index as a predictor, we found that the Moran's Index decreased with the Engel Score (proportional odds model with an odds ratio of 123.01, $p=0.046$ ). $C$, Mean normalized seizure amplitude of patients grouped by Engel Score. There was a significant trend to lower seizure amplitudes for patients with a worse surgical outcome (proportional odds model with an odds ratio of $1.61, p=0.023$.

fluctuations, which is easily identified and subsequently characterized. An alternative approach would be to examine the transition to a specific spatiotemporal pattern and how this transition is organized over the brain, for example, using cross-spectral methods such as Granger's causality (Granger, 1969) or dynamic causal modeling (Moran et al., 2008).

This study was also limited by the restricted spatial sampling of the entire brain's activity. Incomplete coverage of a patient's brain may prevent observation of the earliest recruitment. The observed delay between seizure onset (determined by an epileptologist) and recruitment may represent the time necessary for the ictal activity to spread from a subcortical region to the ECoG grid. We note that the results reported here are consistent with the propagation delays observed during seizure in other studies, e.g., 34.9 s (Brekelmans et al., 1995), 3.8-13.7 s (Götz-Trabert et al., 2008), and 1-45 s (Blume et al., 2001). These delays may be related to the timing of some clinical manifestations including aura and impaired consciousness (Götz-Trabert et al., 2008; Blumenfeld, 2012). The transition to recruitment—a disruptive regime of large voltage fluctuations-likely impairs local neocortices involved in behavior.

\section{Recruitment, network structure, and underlying mechanisms} We showed that the spatial organization of recruitment varied across patients: we found one group of patients for whom the recruitment was spatially organized and stereotyped from seizure to seizure, whereas another group exhibited inconsistent and low spatial organization. We expect that the structure of the connectivity between brain regions would strongly influence the spatiotemporal dynamics of neocortical recruitment, and may account for the different recruitment patterns observed. Using simulations of ictal recruitment in a simple cellular automaton model, we found that networks with stronger local connectivity (i.e., neighbor-to-neighbor compared with small-world networks) induced a more spatially organized and consistent recruitment. This was consistent with the ECoG data, where patients with higher local correlation between electrodes had higher organization of the recruitment. One limitation of the model used in this study is the focus on spatial dynamics, whereas temporal dynamics were not precisely represented. An updated model that includes slow temporal dynamics consistent with the field data (Breakspear et al., 2006; Kim et al., 2009; Kramer et al., 2012; Proix et al., 2014; Meijer et al., 2015) may provide additional insight into the spatiotemporal features of recruitment. The mechanisms of these slow dynamics may include synaptic or nonsynaptic effects such as inhibitory neurons exerting control over the seizing region (McCormick et al., 1985; Bragin et al., 1997; Trevelyan et al., 2006; Cammarota et al., 2013; Hall and Kuhlmann, 2013), extracellular $\mathrm{K}^{+}$accompanying seizure discharges (Lux et al., 1986; Dreier and Heinemann, 1991; Perreault and Avoli, 1992; Durand et al., 2010; Fröhlich et al., 2010), $\mathrm{Ca}^{2+}$. mediated glutamate release from astrocytes (Haydon, 2001; Tian et al., 2005), ephaptic (e.g., electric field) interactions (Holsheimer and Lopes, 1989; Jefferys, 1995; Zhang et al., 2014), or cortico-thalamo-cortical loops (Neckelmann et al., 1998; Bertram et al., 2001; Meeren et al., 2002; Salami et al., 2003; Guye et al., 2006). Extending the modeling approach to incorporate the dynamics of these mechanisms may lead to new insights.

The relationship between network connectivity and recruitment, and seizure activity in general, remains an important research challenge. Different types of diseases or accidents, such as traumatic brain injuries, can induce epilepsy through network changes including neurogenesis and synaptogenesis (Sutula, 2004). Also, during the long-term evolution of the disorder, some anatomical connections can be facilitated or sensitized (Engel, 1996), which could be patient specific (Brekelmans et al., 1995) and produce a diversity in the network structure among patients. We speculate that, for the patients with low spatial organization in our study, the recruitment may not follow a spatially organized propagation, but evolve along more complex features of the anatomical connectivity between neural regions, generating a spatial pattern at the neocortical surface that appears unorganized. Consistent with that idea, spatial inhomogeneities of propagation have been reported in various regions of neocortex (Wadman and Gutnick, 1993; Albowitz and Kuhnt, 1995; Wu et al., 1999; Connors et al., 2001). Also, whether ictal recruitment reflects 
direct neuronal propagation of seizure activity driven by a common source or merely sequential involvement of different potentially epileptogenic structures remains poorly understood (Brekelmans et al., 1995). Invasive measures of brain activity combined with stimulation protocols (Keller et al., 2011) would help better characterize the process of seizure recruitment between interconnected regions.

\section{Relation between the organization of recruitment and surgical outcome}

We found that patients with a spatially organized recruitment pattern (i.e., higher Moran's Index) had improved surgical outcomes. For these patients, recruited areas are more spatially contiguous and therefore potentially more easily identified and resected, leading to an improved surgical outcome. We also reported a link between the Engel Score and the amplitude of seizure activity, which is an easily characterized and nonspatially specific summary characteristic of brain activity. These two measurements could potentially help inform the decision to perform resective surgery, based on the likelihood of success.

The relationship between the spatial characteristics of seizure and the outcome of surgery remains an active research area (Rosenow and Lüders, 2001; Park et al., 2002; Wetjen et al., 2009). Weinand et al. (1992) demonstrated no significant difference in surgical outcome when patients were divided into more focal (fewer than four electrode contacts) and more widespread types of onset. However, Kutsy et al. (1999) qualitatively analyzed ictal spread patterns and reported that the surgical outcome for patients exhibiting slower ictal spread was improved compared with those patients with faster and noncontiguous spread, consistent with the results reported here.

In complex cases when the seizure onset is hard to identify or remove, the spatial properties of a patient's recruitment map could suggest alternative strategies to resective surgery, for example, targeting the cortical pathway of seizure recruitment through disconnection surgery (Morrell et al., 1989) or therapeutic cortical stimulation to disrupt recruitment (Kossoff et al., 2004; Morrell, 2011). In these cases, targeting the immediate recruitment zone, instead of the onset zone, could prove effective (Jenssen et al., 2011) and potentially prevent the recruitment of cortices inducing the strongest impairments for a patient.

\section{References}

Albowitz B, Kuhnt U (1995) Epileptiform activity in the guinea-pig neocortical slice spreads preferentially along supragranular layers-recordings with voltage-sensitive dyes. Eur J Neurosci 7:1273-1284. CrossRef Medline

Andersen P, Silfvenius H, Sundberg SH, Sveen O, Wigström H (1978) Functional characteristics of unmyelinated fibres in the hippocampal cortex. Brain Res 144:11-18. CrossRef Medline

Annegers JF (2001) The epidemiology of epilepsy. In: The treatment of epilepsy: principles and practice (Wyllie E, ed). Philadelphia, PA: Lippincott Williams and Wilkins.

Auer T, Veto K, Dóczi T, Komoly S, Juhos V, Janszky J, Schwarcz A (2008) Identifying seizure-onset zone and visualizing seizure spread by fMRI: a case report. Epileptic Disord 10:93-100. CrossRef Medline

Bertram EH, Mangan PS, Zhang D, Scott CA, Williamson JM (2001) The midline thalamus: alterations and a potential role in limbic epilepsy. Epilepsia 42:967-978. CrossRef Medline

Blenkinsop A, Valentin A, Richardson MP, Terry JR (2012) The dynamic evolution of focal-onset epilepsies - combining theoretical and clinical observations. Eur J Neurosci 36:2188-2200. CrossRef Medline

Blume WT, Ociepa D, Kander V (2001) Frontal lobe seizure propagation: scalp and subdural EEG studies. Epilepsia 42:491-503. CrossRef Medline

Blumenfeld H (2012) Impaired consciousness in epilepsy. Lancet Neurol 11:814-826. CrossRef Medline
Bragin A, Csicsvári J, Penttonen M, Buzsáki G (1997) Epileptic afterdischarge in the hippocampal-entorhinal system: current source density and unit studies. Neuroscience 76:1187-1203. CrossRef Medline

Breakspear M, Roberts JA, Terry JR, Rodrigues S, Mahant N, Robinson PA (2006) A unifying explanation of primary generalized seizures through nonlinear brain modeling and bifurcation analysis. Cereb Cortex 16: 1296-1313. CrossRef Medline

Brekelmans GJF, van Emde Boas W, Velis DN, van Huffelen AC, Debets RMC, van Veelen CWM (1995) Mesial temporal versus neocortical temporal lobe seizures: demonstration of different electroencephalographic spreading patterns by combined use of subdural and intracerebral electrodes. J Epilepsy 8:309-320. CrossRef

Cammarota M, Losi G, Chiavegato A, Zonta M, Carmignoto G (2013) Fast spiking interneuron control of seizure propagation in a cortical slice model of focal epilepsy. J Physiol 591:807-822. CrossRef Medline

Chervin RD, Pierce PA, Connors BW (1988) Periodicity and directionality in the propagation of epileptiform discharges across neocortex. J Neurophysiol 60:1695-1713. Medline

Connors BW, Pinto DJ, Telfeian AE (2001) Local pathways of seizure propagation in neocortex. Int Rev Neurobiol 45:527-546. Medline

Dale AM, Fischl B, Sereno MI (1999) Cortical surface-based analysis: I. Segmentation and surface reconstruction. Neuroimage 9:179-194. CrossRef Medline

de Tisi J, Bell GS, Peacock JL, McEvoy AW, Harkness WF, Sander JW, Duncan JS (2011) The long-term outcome of adult epilepsy surgery, patterns of seizure remission, and relapse: a cohort study. Lancet 378:1388-1395. CrossRef Medline

Dreier JP, Heinemann U (1991) Regional and time dependent variations of low $\mathrm{Mg} 2+$ induced epileptiform activity in rat temporal cortex slices. Exp Brain Res 87:581-596. Medline

Durand DM, Park EH, Jensen AL (2010) Potassium diffusive coupling in neural networks. Philos Trans R Soc Lond B Biol Sci 365:2347-2362. CrossRef Medline

Dykstra AR, Chan AM, Quinn BT, Zepeda R, Keller CJ, Cormier J, Madsen JR, Eskandar EN, Cash SS (2012) Individualized localization and cortical surface-based registration of intracranial electrodes. Neuroimage 59: 3563-3570. CrossRef Medline

Eikermann-Haerter K, Ayata C (2010) Cortical spreading depression and migraine. Curr Neurol Neurosci Rep 10:167-173. CrossRef Medline

Engel J, Van Ness P, Rasmussen T, Ojemann L (1993) Outcome with respect to seizures. In: Surgical treatment of the epilepsies (Engel J, ed), pp $359-$ 367. New York: Raven.

Engel J Jr (1996) Clinical evidence for the progressive nature of epilepsy. Epilepsy Res [Suppl 12]:9-20. Medline

Engel J Jr, Wiebe S, French J, Sperling M, Williamson P, Spencer D, Gumnit R, Zahn C, Westbrook E, Enos B (2003) Practice parameter: temporal lobe and localized neocortical resections for epilepsy: report of the Quality Standards Subcommittee of the American Academy of Neurology, in association with the American Epilepsy Society and the American Association of Neurological surgeons. Neurology 60:538-547. CrossRef Medline

Franaszczuk PJ, Bergey GK, Kamiński MJ (1994) Analysis of mesial temporal seizure onset and propagation using the directed transfer function method. Electroencephalogr Clin Neurophysiol 91:413-427. CrossRef Medline

Fröhlich F, Sejnowski TJ, Bazhenov M (2010) Network bistability mediates spontaneous transitions between normal and pathological brain states. J Neurosci 30:10734-10743. CrossRef Medline

Gotman J (1983) Measurement of small time differences between EEG channels: method and application to epileptic seizure propagation. Electroencephalogr Clin Neurophysiol 56:501-514. CrossRef Medline

Gotman J (1987) Interhemispheric interactions in seizures of focal onset: data from human intracranial recordings. Electroencephalogr Clin Neurophysiol 67:120-133. CrossRef Medline

Götz-Trabert K, Hauck C, Wagner K, Fauser S, Schulze-Bonhage A (2008) Spread of ictal activity in focal epilepsy. Epilepsia 49:1594-1601. CrossRef Medline

Granger CWJ (1969) Investigating causal relations by econometric models and cross-spectral methods. Econometrica 37:424-438. CrossRef

Guye M, Régis J, Tamura M, Wendling F, McGonigal A, Chauvel P, Bartolomei F (2006) The role of corticothalamic coupling in human temporal lobe epilepsy. Brain 129:1917-1928. CrossRef Medline

Hall D, Kuhlmann L (2013) Mechanisms of seizure propagation in 
2-dimensional centre-surround recurrent networks. PLoS One 8:e71369. CrossRef Medline

Harding B, Tremblay C, Cousineau D (2014) Standard errors: a review and evaluation of standard error estimators using Monte Carlo simulations. Quant Methods Psychol 10:107-123.

Haydon PG (2001) GLIA: listening and talking to the synapse. Nat Rev Neurosci 2:185-193. CrossRef Medline

Holsheimer J, Lopes da Silva FH (1989) Propagation velocity of epileptiform activity in the hippocampus. Exp Brain Res 77:69-78. CrossRef Medline

Holtkamp M, Buchheim K, Siegmund H, Meierkord H (2003) Optical imaging reveals reduced seizure spread and propagation velocities in aged rat brain in vitro. Neurobiol Aging 24:345-353. CrossRef Medline

Jefferys JG (1995) Nonsynaptic modulation of neuronal activity in the brain: electric currents and extracellular ions. Physiol Rev 75:689-723. Medline

Jenssen S, Roberts CM, Gracely EJ, Dlugos DJ, Sperling MR (2011) Focal seizure propagation in the intracranial EEG. Epilepsy Res 93:25-32. CrossRef Medline

Jirsa VK, Stacey WC, Quilichini PP, Ivanov AI, Bernard C (2014) On the nature of seizure dynamics. Brain 137:2210-2230. CrossRef Medline

Keller CJ, Bickel S, Entz L, Ulbert I, Milham MP, Kelly C, Mehta AD (2011) Intrinsic functional architecture predicts electrically evoked responses in the human brain. Proc Natl Acad Sci U S A 108:10308-10313. CrossRef Medline

Keränen T, Sillanpää M, Riekkinen PJ (1988) Distribution of seizure types in an epileptic population. Epilepsia 29:1-7. CrossRef Medline

Keränen T, Riekkinen PJ, Sillanpää M (1989) Incidence and prevalence of epilepsy in adults in eastern Finland. Epilepsia 30:413-421. CrossRef Medline

Kim JW, Roberts JA, Robinson PA (2009) Dynamics of epileptic seizures: evolution, spreading, and suppression. J Theor Biol 257:527-532. CrossRef Medline

Kossoff EH, Ritzl EK, Politsky JM, Murro AM, Smith JR, Duckrow RB, Spencer DD, Bergey GK (2004) Effect of an external responsive neurostimulator on seizures and electrographic discharges during subdural electrode monitoring. Epilepsia 45:1560-1567. CrossRef Medline

Kramer MA, Eden UT, Kolaczyk ED, Zepeda R, Eskandar EN, Cash SS (2010) Coalescence and fragmentation of cortical networks during focal seizures. J Neurosci 30:10076-10085. CrossRef Medline

Kramer MA, Truccolo W, Eden UT, Lepage KQ, Hochberg LR, Eskandar EN, Madsen JR, Lee JW, Maheshwari A, Halgren E, Chu CJ, Cash SS (2012) Human seizures self-terminate across spatial scales via a critical transition. Proc Natl Acad Sci U S A 109:21116-21121. CrossRef Medline

Kutsy RL, Farrell DF, Ojemann GA (1999) Ictal patterns of neocortical seizures monitored with intracranial electrodes: correlation with surgical outcome. Epilepsia 40:257-266. CrossRef Medline

Lee SA, Spencer DD, Spencer SS (2000) Intracranial EEG seizure-onset patterns in neocortical epilepsy. Epilepsia 41:297-307. CrossRef Medline

Lewis TJ, Rinzel J (2000) Self-organized synchronous oscillations in a network of excitable cells coupled by gap junctions. Network 11:299-320. CrossRef Medline

Lieb JP, Engel J Jr, Babb TL (1986) Interhemispheric propagation time of human hippocampal seizures. I. Relationship to surgical outcome. Epilepsia 27:286-293. CrossRef Medline

Lieb JP, Hoque K, Skomer CE, Song XW (1987) Inter-hemispheric propagation of human mesial temporal lobe seizures: a coherence/phase analysis. Electroencephalogr Clin Neurophysiol 67:101-119. CrossRef Medline

Litt B, Esteller R, Echauz J, D’Alessandro M, Shor R, Henry T, Pennell P, Epstein C, Bakay R, Dichter M, Vachtsevanos G (2001) Epileptic seizures may begin hours in advance of clinical onset: a report of five patients. Neuron 30:51-64. CrossRef Medline

Lopes da Silva F, Blanes W, Kalitzin SN, Parra J, Suffczynski P, Velis DN (2003) Epilepsies as dynamical diseases of brain systems: basic models of the transition between normal and epileptic activity. Epilepsia 44 Suppl 1:72-83. CrossRef Medline

Lux HD, Heinemann U, Dietzel I (1986) Ionic changes and alterations in the size of the extracellular space during epileptic activity. Adv Neurol 44: 619-639. Medline

McCormick DA, Contreras D (2001) On the cellular and network bases of epileptic seizures. Annu Rev Physiol 63:815-846. CrossRef Medline
McCormick DA, Connors BW, Lighthall JW, Prince DA (1985) Comparative electrophysiology of pyramidal and sparsely spiny stellate neurons of the neocortex. J Neurophysiol 54:782-806. Medline

Meeren HK, Pijn JP, Van Luijtelaar EL, Coenen AM, Lopes da Silva FH (2002) Cortical focus drives widespread corticothalamic networks during spontaneous absence seizures in rats. J Neurosci 22:1480-1495. Medline

Meijer HG, Eissa TL, Kiewiet B, Neuman JF, Schevon CA, Emerson RG, Goodman RR, McKhann GM Jr, Marcuccilli CJ, Tryba AK, Cowan JD, van Gils SA, van Drongelen W (2015) Modeling focal epileptic activity in the Wilson-Cowan model with depolarization block. J Math Neurosci 5:7. CrossRef Medline

Moran PA (1950) Notes on continuous stochastic phenomena. Biometrika 37:17-23. CrossRef Medline

Moran RJ, Stephan KE, Kiebel SJ, Rombach N, O’Connor WT, Murphy KJ, Reilly RB, Friston KJ (2008) Bayesian estimation of synaptic physiology from the spectral responses of neural masses. Neuroimage 42:272-284. CrossRef Medline

Morrell F, Whisler WW, Bleck TP (1989) Multiple subpial transection: a new approach to the surgical treatment of focal epilepsy. J Neurosurg 70:231-239. CrossRef Medline

Morrell MJ (2011) Responsive cortical stimulation for the treatment of medically intractable partial epilepsy. Neurology 77:1295-1304. CrossRef Medline

Mosteller F, Tukey JW (1977) Data analysis and regression: a second course in statistics. Upper Saddle, NJ: Pearson.

Neckelmann D, Amzica F, Steriade M (1998) Spike-wave complexes and fast components of cortically generated seizures. III. Synchronizing mechanisms. J Neurophysiol 80:1480-1494. Medline

Netoff TI, Clewley R, Arno S, Keck T, White JA (2004) Epilepsy in smallworld networks. J Neurosci 24:8075-8083. CrossRef Medline

Nevado-Holgado AJ, Marten F, Richardson MP, Terry JR (2012) Characterising the dynamics of EEG waveforms as the path through parameter space of a neural mass model: application to epilepsy seizure evolution. Neuroimage 59:2374-2392. CrossRef Medline

Park SA, Lim SR, Kim GS, Heo K, Park SC, Chang JW, Chung SS, Choi JU, Kim TS, Lee BI (2002) Ictal electrocorticographic findings related with surgical outcomes in nonlesional neocortical epilepsy. Epilepsy Res 48: 199-206. CrossRef Medline

Perreault P, Avoli M (1992) 4-aminopyridine-induced epileptiform activity and a GABA-mediated long-lasting depolarization in the rat hippocampus. J Neurosci 12:104-115. Medline

Perucca P, Dubeau F, Gotman J (2014) Intracranial electroencephalographic seizure-onset patterns: effect of underlying pathology. Brain 137: 183-196. CrossRef Medline

Peterson BM, Ferrarese L, Gilbert KM, Kaspi S, Malkan MA, Maoz D, Merritt D, Netzer H, Onken CA, Pogge RW, Vestergaard M, Wandel A (2004) Central masses and broad-line region sizes of active galactic nuclei. II. A homogeneous analysis of a large reverberation-mapping database. Astrophys J 613:682-699. CrossRef

Pinto DJ, Patrick SL, Huang WC, Connors BW (2005) Initiation, propagation, and termination of epileptiform activity in rodent neocortex in vitro involve distinct mechanisms. J Neurosci 25:8131-8140. CrossRef Medline

Proix T, Bartolomei F, Chauvel P, Bernard C, Jirsa VK (2014) Permittivity coupling across brain regions determines seizure recruitment in partial epilepsy. J Neurosci 34:15009-15021. CrossRef Medline

Rosenow F, Lüders H (2001) Presurgical evaluation of epilepsy. Brain 124: 1683-1700. CrossRef Medline

Salami M, Itami C, Tsumoto T, Kimura F (2003) Change of conduction velocity by regional myelination yields constant latency irrespective of distance between thalamus and cortex. Proc Natl Acad Sci U S A 100: 6174-6179. CrossRef Medline

Schevon CA, Weiss SA, McKhann G Jr, Goodman RR, Yuste R, Emerson RG, Trevelyan AJ (2012) Evidence of an inhibitory restraint of seizure activity in humans. Nat Commun 3:1060. CrossRef Medline

Schindler K, Leung H, Elger CE, Lehnertz K (2007) Assessing seizure dynamics by analysing the correlation structure of multichannel intracranial EEG. Brain 130:65-77. CrossRef Medline

Soltesz I, Staley KJ eds (2011) Computational neuroscience in epilepsy. London: Academic. 
Sonmezturk HH, Morgan V, Abou-Khalil B (2011) Focal seizure propagation illustrated by fMRI. Epileptic Disord 13:92-95. CrossRef Medline

Spencer SS, Marks D, Katz A, Kim J, Spencer DD (1992) Anatomic correlates of interhippocampal seizure propagation time. Epilepsia 33:862873. CrossRef Medline

Sutula TP (2004) Mechanisms of epilepsy progression: current theories and perspectives from neuroplasticity in adulthood and development. Epilepsy Res 60:161-171. CrossRef Medline

Tian GF, Azmi H, Takano T, Xu Q, Peng W, Lin J, Oberheim N, Lou N, Wang X, Zielke HR, Kang J, Nedergaard M (2005) An astrocytic basis of epilepsy. Nat Med 11:973-981. Medline

Towle VL, Carder RK, Khorasani L, Lindberg D (1999) Electrocorticographic coherence patterns. J Clin Neurophysiol 16:528-547. CrossRef Medline

Traub RD, Schmitz D, Jefferys JG, Draguhn A (1999) High-frequency population oscillations are predicted to occur in hippocampal pyramidal neuronal networks interconnected by axoaxonal gap junctions. Neuroscience 92:407-426. CrossRef Medline

Traub RD, Duncan R, Russell AJ, Baldeweg T, Tu Y, Cunningham MO, Whittington MA (2010) Spatiotemporal patterns of electrocorticographic very fast oscillations $(>80 \mathrm{~Hz})$ consistent with a network model based on electrical coupling between principal neurons. Epilepsia 51: 1587-1597. CrossRef Medline

Trevelyan AJ, Sussillo D, Watson BO, Yuste R (2006) Modular propagation of epileptiform activity: evidence for an inhibitory veto in neocortex. J Neurosci 26:12447-12455. CrossRef Medline
Wadman WJ, Gutnick MJ (1993) Non-uniform propagation of epileptiform discharge in brain slices of rat neocortex. Neuroscience 52:255-262. CrossRef Medline

Watts DJ, Strogatz SH (1998) Collective dynamics of "small-world" networks. Nature 393:440-442. CrossRef Medline

Weinand ME, Wyler AR, Richey ET, Phillips BB, Somes GW (1992) Longterm ictal monitoring with subdural strip electrodes: prognostic factors for selecting temporal lobectomy candidates. J Neurosurg 77:20-28. CrossRef Medline

Wetjen NM, Marsh WR, Meyer FB, Cascino GD, So E, Britton JW, Stead SM, Worrell GA (2009) Intracranial electroencephalography seizure onset patterns and surgical outcomes in nonlesional extratemporal epilepsy. J Neurosurg 110:1147-1152. CrossRef Medline

Wolfram S (2002) A new kind of science. Campaign, IL: Wolfram Media.

Wong BY, Prince DA (1990) The lateral spread of ictal discharges in neocortical brain slices. Epilepsy Res 7:29-39. CrossRef Medline

Wu JY, Guan L, Tsau Y (1999) Propagating activation during oscillations and evoked responses in neocortical slices. J Neurosci 19:5005-5015. Medline

Zarrelli MM, Beghi E, Rocca WA, Hauser WA (1999) Incidence of epileptic syndromes in Rochester, Minnesota: 1980-1984. Epilepsia 40:17081714. CrossRef Medline

Zhang M, Ladas TP, Qiu C, Shivacharan RS, Gonzalez-Reyes LE, Durand DM (2014) Propagation of epileptiform activity can be independent of synaptic transmission, gap junctions, or diffusion and is consistent with electrical field transmission. J Neurosci 34:1409-1419. CrossRef Medline 